\title{
An overview of optical and thermal methods for the characterization of carbonaceous aerosol
}

\author{
D. Massabò ${ }^{1}$. P. Prati $^{1}$
}

Received: 30 October 2020 / Accepted: 6 March 2021 / Published online: 9 April 2021

(C) The Author(s) 2021

\begin{abstract}
Carbon is present in the atmosphere not only as $\mathrm{CO}_{2}$ and other gaseous compounds: it is also one of the major components of the atmospheric aerosols. Carbonaceous Aerosols, CA, have a high but still not fully understood impact on climate and human health, furthermore, their composition is part of the "fingerprint" characteristic of different "sources" of airborne Particulate Matter (PM). The set of methodologies to quantify the concentration of specific carbonaceous species in the atmospheric aerosols is extremely ample, however a completely assessed standard has not been defined yet. In this review article we summarize the state of the art in such wide and multi-disciplinary field, with a focus on optical and thermo-optical methodologies and insights on the more relevant open problems.
\end{abstract}

Keywords Atmospheric particulate matter - Carbonaceous aerosol - Optical and thermo-optical anlysis · Source apportionment

\section{Introduction}

Carbon is a very special element because its intrinsic relationship with the life, undoubtedly the most complex and mysterious of chemical reactions: every organism is built around carbon atoms. In the atmospheric environment, carbon plays an important and variegated role.

The presence and the impact of carbon in the atmosphere is part of the huge topic of the climate change and of the debate on its forcing variables. In this frame, a primary and well known role is played by $\mathrm{CO}_{2}$ with an enormous and consolidated literature (e.g [1,2]). Actually, the climate forcing due to the increasing atmospheric concentration of $\mathrm{CO}_{2}$ and other Greenhouse gases (GHGs), first of all $\mathrm{CH}_{4}$, is well assessed with an overall uncertainty of about $10 \%\left(\mathrm{CO}_{2}\right.$ forcing $=1.8 \pm 0.2 \mathrm{~W} \mathrm{~m}^{-2}$; total GHGs:

P. Prati

prati@ge.infn.it

1 Dipartimento di Fisica, Università di Genova and INFN, Sezione di Genova, Genova, Italy 


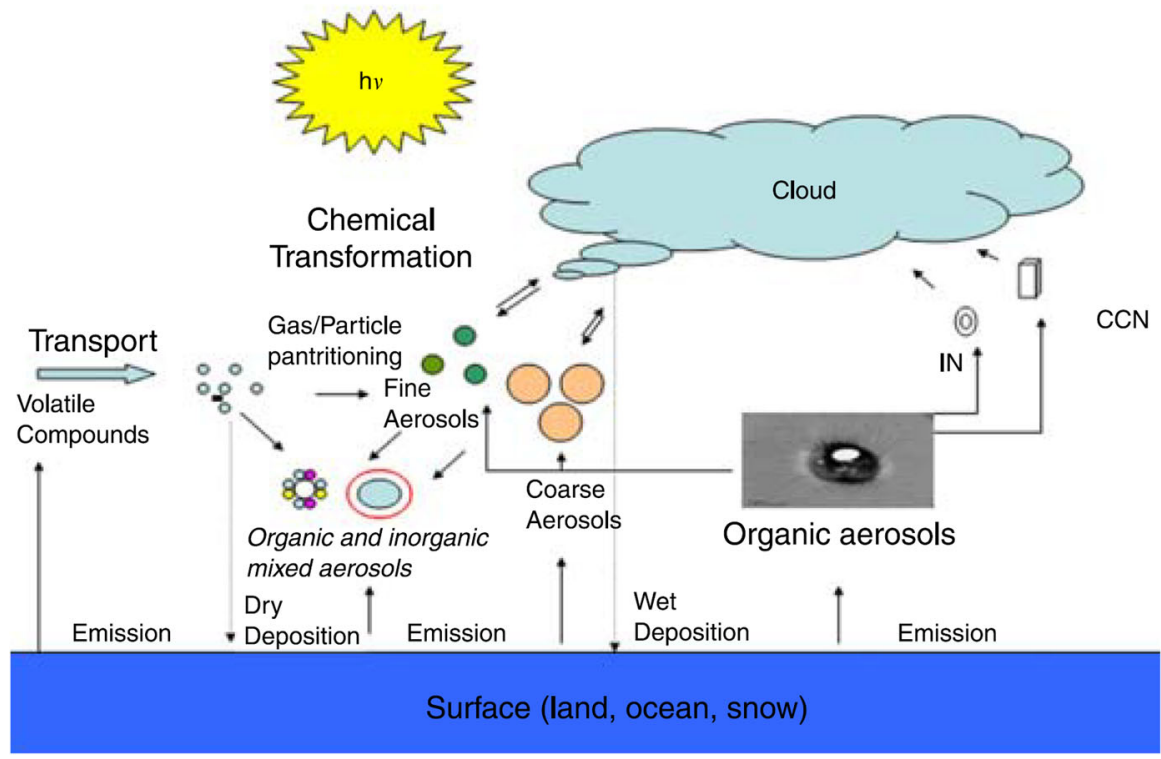

Fig. 1 Transformation and processes of organic aerosol in the atmosphere leading to CCN and IN (Ice Nuclei) and finally to cloud formation. Extracted from [7]

$2.9 \pm 0.3 \mathrm{~W} \mathrm{~m}^{-2}$; [3]). However, the climatic impact of carbon is, at the same time, much wider and less firm when enlarging the analysis to include the atmospheric aerosols. Organic and inorganic carbonaceous compounds are a major component of atmospheric aerosols, mainly those with anthropogenic origin [4]. Most of the present uncertainty on the total climate forcing is associated to the direct and indirect effect of atmospheric aerosols (i.e. $-1.0 \pm 1.2 \mathrm{~W} \mathrm{~m}^{-2}$, [3,5]) with specific issues on carbonaceous compounds. An example is the darkening of glaciers surface due to the deposition of carbonaceous particulate matter with a double self-feeding effect: the decrease of the planetary albedo and the speed-up of ice melting [6]. Both the effects have a positive (i.e. warming) effect on the global climate. A quantity of studies on atmospheric aerosols have shown that organic aerosols induce relevant indirect effects being part of the part of the global cloud condensation nuclei $(\mathrm{CCN})$ budget(e.g [7]). CCN are aerosol particles that with high concentration of supersaturated water vapour [8] activate an evolve forming cloud and fog droplets. Actually, the activation capability of organic aerosols is comparable to that of sulfate aerosols, which are considered the most effective CCN [9]. Beside, bacteria and other components of the atmospheric bioaerosol are as well known to favour the cloud formations and therefore to indirectly cause a negative (i.e. cooling) forcing on climate $[10,11]$. Primary biological aerosol particles are efficient $\mathrm{CCN}$, provided that their surfaces are wettable [12,13].The microbiological degradation of organic compounds as possible mechanism to enhance the ability of organics to act in the troposphere as $\mathrm{CCN}$ as been also reported [14]. A cartoon view of the interplay between carbonaceous and other aerosols and meteorological conditions leading to clouds formation is given in Fig. 1

CA as other components of atmospheric PM have an impact on visibility too, through absorption and scattering of the light $[4,15]$. Aerosols scatter and absorb light 
depending on the particle size. The Mie scattering theory can be used to approximate the amount of scattering and absorption when the distribution of particle size and the refractive index (which depend on particle composition) are both known [16]. In this frame, combustion-generated aerosols are rich in carbon and strongly absorb electromagnetic radiation over the entire visible spectrum: actually, they are the most efficient absorbers of solar radiation [4,17].

The relationship between air quality and human health is another extremely ample field where carbon compounds are protagonist actors. The harmful effect of gaseous molecules like carbon mono-oxide is historically fully assessed and the toxicity/pathogenic load of many organic molecules is also well know even as a more recent achievement (e.g. [18]). Effects of atmospheric aerosols on the health of human beings are also quite well established and, for instance, the monitoring of PM10 and PM2.5 (PM with aerodynamic diameter $\leq 10 \mu \mathrm{m}$ and $2.5 \mu \mathrm{m}$, respectively) levels is prescribed and limit values are set in accordance with the European Directive 2008/50/EC and similar regulatory acts in other countries. At background sites, ionic and carbonaceous speciation is also prescribed for PM2.5. An example of the worldwide distribution of carbonaceous and other species present in the atmospheric aerosols is reported in Fig. 2.

The emission of CA result in ground level concentrations which can reach several tens of $\mu \mathrm{g} \mathrm{m}^{-3}$ and a fraction of the total PM up to $50 \%$. Highest CA concentration values are typical of urban areas densely populated as Beijng [20], New Delhi [21] and other megalopolis [22,23]. Lower concentration of both PM and CA are usually measured in urban and rural sites of USA (e.g. [24,25]) and Europe (e.g. [26,27]). In Italy, highest concentration values are typical of the Po valley and of major urban sites as reported in the review [28], from which Fig. 3 has been extracted.

In recent years, a number of epidemiological studies highlighted the link between exposure to PM and several health effects, mainly on the respiratory and cardiovascular system, as well as premature deaths $[29,30]$. The toxicological mechanisms associated with PM at cellular level, such as cytotoxicity through oxidative stress, oxygen-free radical-generating activity, DNA oxidative damage, mutagenicity, and the stimulation of pro-inflammatory responses, are currently unclear [31]. The role of chemical composition influences ecotoxicity, cytotoxicity, and genotoxicity in different ways, so that different biological effects are possible even with same values of PM and/or particle number concentration [32]. Actually, the exposure to soot was first associated with skin cancer of the scrotum among British chimney sweeps in 1775. From the first evidences, a long series of observations followed and this recently resulted, for instance, in the suggestion to use Elemental Carbon, EC, (see Sect. 2) as a better proxy for harmful PM from combustion sources, especially from diesel exhaust [33]. The inclusion of an EC-PM2.5 standard in the list of monitored/regulated pollutants has then been proposed for a firmer evaluation of traffic pollution impacts in urban areas $[34,35]$.

Health effects are of course related to the biological component of atmospheric aerosol (bioaerosol) too. From the pioneer investigations at the end of the nineteenth century [36], the study of primary biological aerosol particles (PBAP) has become a multidisciplinary field of research where fungal spores and bacteria play an important role $[37,38]$. Bacteria concentration in the outdoor atmosphere ranges from $10^{4}$ to $10^{6}$ 
(a)
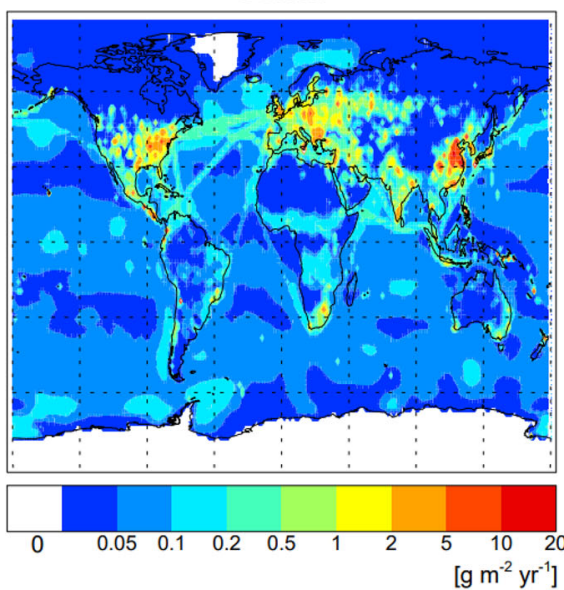

(c)
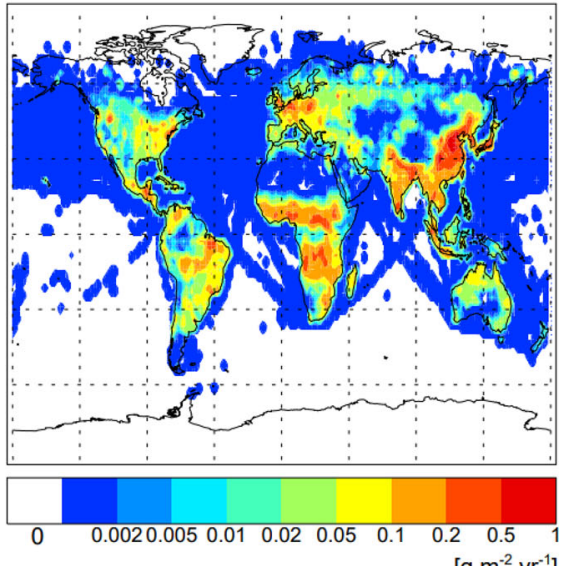

(b) Sea Salt
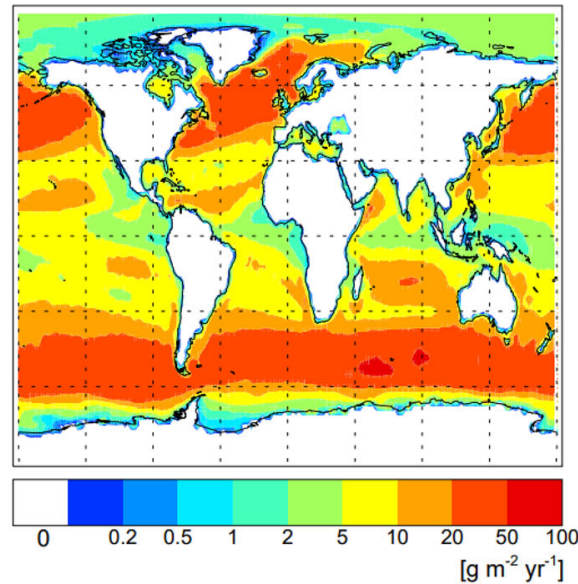

(d) Particulate Organic Matter
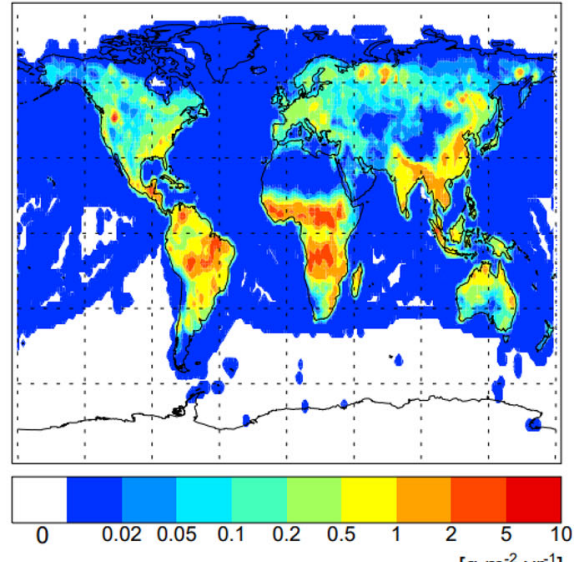

$\left[\mathrm{g} \mathrm{m}^{-2} \mathrm{yr}^{-1}\right]$

Fig. 2 Annual mean emission distribution by species in the atmospheric aerosols. The term "Black Carbon" refers to the elemental, strongly absorbing, carbon particles better defined in Sect. 2. The maps have been extracted from [19] and have been produced by a global climate model

cells $\mathrm{m}^{-3}$ [39] with a wide range of diversity [40,41]. Bacterial and fungi viability depends on the interaction between bacteria and the other constituents in the atmospheric medium including the not-biologic aerosol: such interplay is still far from a satisfactory understanding $[42,43]$.

Even this short and incomplete introduction highlights the preeminent and variegate importance of CA, including the biological component, for human health and the puzzle of climate change. Despite such role is fully understood by the thousands of scientists who worldwide study the atmospheric aerosols, still there is a wide lack of knowledge on the temporal and spatial variability of aerosol particles and their properties, including the organic and inorganic components of the carbonaceous fraction. 


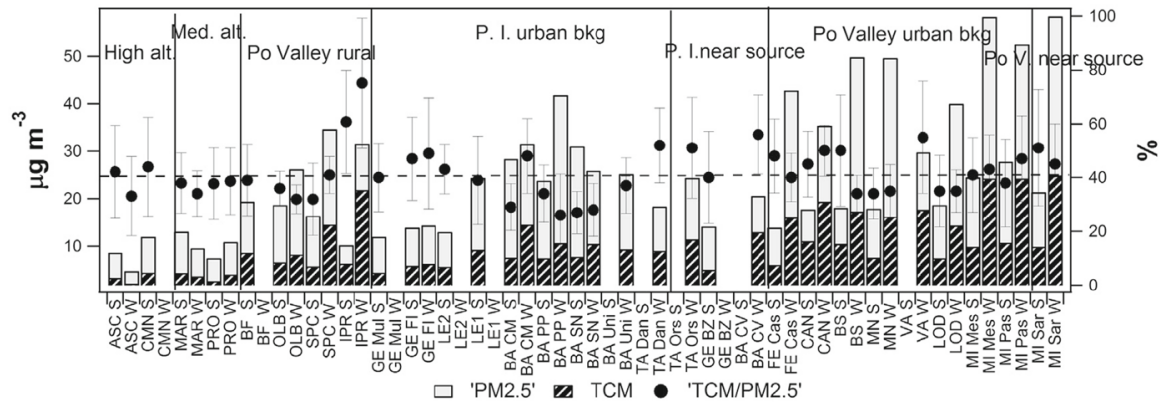

Fig. 3 Summer and winter PM2.5 mass concentrations (grey) and superimposed Total Carbon Mass (TCM) at 30 italian sites with measurements on PM2.5. The sites are subdivided on a regional basis in Peninsular Italy (P.I.) and Po Valley and on the distance from emission sources in urban background and near-source (industrial and traffic) sites. The relative contribution of TCM to PM2.5 is reported as black dots, with bars corresponding to one standard deviation. The correspondence between labels and geographical position is given in the original article [28]

This review aims to summarize the state of the art on the polyhedric presence of carbon in the atmospheric aerosol trying to identify the most relevant issues to be faced in the next future. The topic is so wide that a selection of the most relevant aspects is unavoidable and the authors are conscious of the limits of their work.

\section{Carbonaceous compounds in the atmospheric aerosols}

The science of atmospheric aerosol is a multidisciplinary field which received contributes from various disciplines and expertise in different periods. This peculiar situation is reflected in the variety of definitions and names introduced to identify the whole or single components of the PM dispersed in the atmosphere [44]. In addition, the PM itself is intrinsically poorly defined given the variability in dimension, shape, composition and origin. This level of complexity is largely present in the sub-topic of CA even disregarding the numerous variants of bioaerosol particles. Actually, the segregation of carbon in viruses, bacteria, fungi, spores, pollen, etc. refers to broader biological classifications which do not deserve further clarification. The situation is much more confused in the apparently simpler case of inorganic and organic compounds. In the literature there are several review works which face this issue and try to order and simplify the landscape, in particular focusing on the properties which determine the interaction of CA with electromagnetic radiation [4,45]. We first list in Table 1 a number of abbreviations adopted in the literature as well as in this work. Each acronym is briefly defined in the following:

$\boldsymbol{T C}$ is the total mass of carbon in an aerosol sample (e.g. in the material deposited on a filter or other support utilized to concentrate the PM in a given volume of atmosphere in a suitable collecting media). Frequently, TC is measured by thermal evolution [46] or thermo-optical analysis [47].

$\boldsymbol{O C}$ is the fraction of TC contained in organic molecules. While the definition is clear, the experimental methodologies to determine the OC concentration suffer of several artifacts and systematics so that OC should be considered as an operative 
Table 1 Principal acronyms for carbonaceous aerosol and related quantities

\begin{tabular}{ll}
\hline TC & Total carbon \\
OC & Organic carbon \\
EC & Elemental carbon \\
BC & Black carbon \\
EBC & Equivalent black carbon \\
rBC & Refractory black carbon \\
BrC & Brown carbon \\
OM & Organic matter \\
PYRC & Pyrolitic carbon \\
HULIS & Humic-like substances \\
LAC & Light absorbing carbon \\
MAC & Mass absorption coefficient \\
SSA & Single scattering albedo \\
SOA & Secondary organic aerosol \\
\hline
\end{tabular}

definition, strictly related to the instrumental approach adopted to retrieve its value [4, 47,48].

$\boldsymbol{E C}$ is the fraction of TC carbon which does not volatilize at low temperature, usually below 550 [4]. As for OC, the EC definition has an operational basis which relies on the stability of carbon at elevated temperatures [47-49]. A strong correlation between light absorption and EC content in the PM is commonly found, however the quantitative link between EC and PM optical properties can not be assessed in general terms [4].

$\boldsymbol{B C}$ is also operationally defined as the TC fraction which shows a high absorption across a wide spectrum of visible and infrared wavelengths [4], due to a significant nonzero imaginary part $k$ of the refractive index, with $k \approx 0.79[4,45]$. The acronym BC is frequently used to identify the results of optical determination of the carbon content in the PM, as in the case of attenuation [17] and/or absorption [50] measurements.

$\boldsymbol{E B C}$ has been introduced in the article [51] as recommendation to be followed with the results of optical determination of BC. The Authors suggested the use of EBC instead of BC for data derived from optical absorption methods. EBC values should be delivered together with a suitable MAC (see below) for the conversion of light absorption coefficient into mass concentration. Furthermore, EBC data should be completed with a description of the approach used for separating potential contributions of $\mathrm{BrC}$ (see below) or other components, as mineral dust, to the aerosol light absorption coefficient.

$\boldsymbol{r} \boldsymbol{B C}$ has been introduced to define the BC measured by means of incandescence methods, since these methods mainly address the thermal stability of the carbonaceous matter and require light-absorbing efficiency of the analyzed PM [51].

$\boldsymbol{B r C}$ has a brownish or yellowish appearance and corresponds to a class of organic light-absorbing carbonaceous compounds with an imaginary part of the refractive index that increases moving toward short-visible and UV wavelengths [45]. This behaviour is different from the trend of light absorption by $\mathrm{BC}$ [55]. $\mathrm{BrC}$ is a fraction 
of OC generally associated to biomass burning [45]: it is worthy to note that Organic Carbon (OC) has been and is generally assumed to not have any significant absorption in the visible spectral region. However, this is not the case of $\mathrm{BrC}$ which could have, for instance, a sizeable effect on radiative forcing and on the assumption at the basis of widespread instruments/methodologies [47] (see section "Experimental issues"). Despite the increasing interest on $\mathrm{BrC}$, the efforts to clearly define and characterize its origin and properties are still far from a satisfactory conclusion [56].

$\boldsymbol{O M}$ the OC definition refers to the mass or concentration of Carbon only, however organic carbonaceous particles obviously includes other atomic species. The total mass of organic particles is instead accounted by OM. In the literature there are several studies which propose multiplicative coefficients to calculate OM from the OC values and depending on the composition and ageing of the carbonaceous particles. Such coefficients usually vary from 1.6 (for urban sites) to 2.1 (for rural/remote sites) as detailed in the review work [53].

PYRC is usually formed during the thermal evolution of PM samples in an inert atmosphere (see section "Experimental issues"): with temperatures of hundreds of Celsius, the most refractive organic components are dissociated and can form inorganic residuals. Such pyrolysis products get mixed with the EC originally present in the sample and significantly alter its quantification [4].

HULIS include organic molecules in PM which can be isolated from fog and cloud water and show a similarity to terrestrial and aquatic humic and fulvic acids [54]. HULIS raised interest since they may affect aerosol properties: they can nucleate cloud droplets and show the capacity to absorb light [54].

$\boldsymbol{L A C}$ is a generic term including all the carbonaceous species in the atmospheric aerosols which can absorb electromagnetic radiation [4] in the visible or near-visible interval of wavelengths.

$\boldsymbol{M A C}$ has been firstly introduced by [4] with the aim to set an unambiguous quantitative definition of the light absorbing properties of atmospheric aerosols. MAC is the light absorption cross section normalized to the mass of a given species (e.g. BC and/or BrC) of aerosol particles. MAC is given in units of $\left(\mathrm{m}^{2} \mathrm{~g}^{-1}\right)$ both for absorption or scattering cross section.

SSA the single-scattering albedo, is the ratio between scattering and extinction (absorption plus scattering) cross section. This is a quite general definition [16] extremely relevant for CA (see section "Experimental issues"). Aerosol species with SSA close to one, extinct light primarily by scattering. With lower SSA values, the aerosols can progressively absorb light resulting in positive climate forcing at SSA $\leq 0.85$ [57].

SOA are a wide class of secondary aerosols formed by oxidation of gasphase organics in the atmosphere. Actually, in the atmosphere thousands of volatile and semi-volatile organic compounds, eventually with primary origin, continuously react with $\mathrm{OH}$ radicals and ozone and other oxidants, leading to to the formation of SOA i.e. different organic products, likely with lower volatility and higher solubility ( [58] and references therein). 


\section{Effects and impact of the carbonaceous aerosols}

CA contribute to the variegate impact of PM on human health and the total environment. While some effects are shared with any other PM components, CA have specific and very significant impacts as summarized in the following sub-sections.

\subsection{Health effects}

The main and still open issue on the health effects of CA can be summarized in one single question: do CA or any their specific component (or mixing) have an impact on human heath significantly different from the figure assumed for PM? Actually, as introduced in Sect. 1, the present regulatory frame on air quality adopts a metric based on PM concentration without any link to its composition. However, as a result of an ample an deep review on the knowledge of PM composition and effects, Fuzzi and coworkers [59] underlined as a major challenge for the research in the field, the assessment of the relationship between chemical constituents of PM and health effects. They highlighted the importance of reactive species in PM particles (e.g. peroxides, radicals, metals) and of the change of their composition due to secondary processes. A similar conclusion was formulated at the end of the CARE (Carbonaceous Aerosol in Rome and Environs) experiment [60]: the study provided baseline levels of CA for the city of Rome and claimed the need for an update of existing air quality standards for PM10 and PM2.5 with regard to particle composition and size distribution.

The hypothesis of specific health effects directly related to EC exposure has been reviewed in the work by Olstrup and coworkers [61]. In this article, a set of data collected in different site and periods are analyzed to find the correlation between the relative risk of mortality (for all-cause, cardiovascular and respiratory diseases) and short-term exposure to PM10 and EC. The quantitative study is affected by large uncertainties also due to the fact that, in several cases, the EC concentration had to be retrieved from original data expressed in term of "Black Smoke". The old Black-Smoke method is based on the reflection of visible light from the soot deposited on a filter: the quantitative relationship with EC is largely method-dependent [62]. According to Olstrup and coworkers [61], the lack of really comparable set of data (i.e. not affected by large and uncontrolled systematic uncertainties) prevent the possibility of any firm conclusion: while the review ends with some claims on a possible risk of mortality directly correlated with EC (and ten-times higher than the risk retrieved for PM10), the last sentence asks urgently for "a more specific and standardized methodology for measuring combustion-related particles" (see Sect. 4). A second study of the same group focuses on BC [63]. The work considers data from three major Swedish cities (Stockholm, Gothenburg and Umea) and exploits experimental results and dispersion model analyses to take into account both the impact of local sources and of Long Range Transport (LRT) polluted air masses. The main Authors claim is that using relative risk factors and assuming BC as indicator of PM from local combustion sources, the local sources of PM turn out to cause more premature deaths as compared to LRT. When risk assessments are instead based on the total PM10 or PM2.5, LRT produces a larger impact with a resulting of underestimating the impact of local sources. Several 
other studies performed in different sites worldwide (e.g. [64-67]) converge to similar conclusions, in particular when looking for the best sanitary indicator for the risk to the exposure to fossil or biomass combustion. On the possible specific health effect of $\mathrm{EC}$ or $\mathrm{BC}$, a comprehensive and firm picture is still largely missing and, almost ten years later, the conclusion of the WHO office for Europe [68]: "At present, it is not possible to say definitively whether health effects due to exposure to BC or PM mass are different qualitatively (for example, different health outcomes) and/or quantitatively from each other", is still valid.

A further step in complexity is necessary to discuss the specific effect of OC. The topic has been reviewed by Mauderly and Chow [69]. The Authors first remember that the US Clean Air Act includes in the list of 188 "hazardous air pollutants" several organic species, most of them being PAHs (Polycyclic Aromatic Hydrocarbons) or compounds with a significant fraction of organic molecules. The amount of supporting epidemiological evidences and studies is large ( [69] and references therein) but the topic is analyzed mainly in term of "key knowledge gaps". While OC is firmly considered an important contributor to cancer risks associated with air pollution, many other possible effects remain questionable, mainly due to the lack of systematic and comparable monitoring and PM speciation. Among the possible adverse health effects attributable to $\mathrm{OC}$, the Authors quote protein-specific allergies, binding to specific cellular receptors, or compound-specific covalent binding with bio-molecules such as the formation of DNA adducts. Moreover, the organic response to air pollution is usually due to a mix/sum of factors and OC is indicated as possible co-agent of lung inflammation, reduced lung function, allergic response, asthma exacerbation, heart arrhythmia, or myocardial infarction. A quantitative assessment of the risk associated to $\mathrm{OC}$ is presently not available. The basic assumption of a linear dose-response seems biologically unlikely even there is not enough information to refine the default assumption. Epidemiological studies usually fail in determine with accuracy personal exposures, since the variability in the personal response complicates the identification of risk thresholds. As common in other fields, first of all the protection against ionizing radiations (see for example [70]), Mauderly and Chow complain that unrealistic high doses are commonly accepted as confirming hazard and supporting plausibility for effects of environmental exposures. Finally, they stress that a deep understanding of the biological mechanism linking the exposure to OC with specific health effects will be the essential step toward a realistic dose-response curve.

To conclude this short overview it is just worthy to come back to the most direct evidence for the health effects of environmental organic aerosols: the several pathologies induced by bio-aerosol particles (viruses, bacteria, pollens, spores, and plant and animal debris). Even if such evidence had been already recognized in the nineteenth century, it is often overlooked in the study of relationships between air quality and health. The interplay between gaseous and aerosol pollutants and the diffusion, viability and pathogenecity of bioaerosol components has been tentatively addressed by a few pilot studies [71,72] exploiting new facilities as the atmospheric simulation chambers [73], an approach that will likely find new and systematic applications in the mid-term future to complement in-field experiments [74]. 


\subsection{Environmental impact}

Despite health effects are usually the first and main factor in attracting attention toward the air pollution, CA are suspected to have such a large, long-term impact on the environment to overcome the specific and immediate sanitary issues. Actually, in the last years the number of peer-review articles dealing with the climatic effects of atmospheric aerosol was around 2000 per year to be compared with about 1300 article per year on more traditional air quality topics [59]. This is why the environmental issues have been listed as first in the Introduction of this review. The environmental role of CA is so ample to require a separate discussion for four (broad) areas that we consider of main interest: Climate forcing, Ice darkening, Visibility reduction, Cultural Heritage deterioration.

\subsubsection{Climate forcing}

The budgetary numbers which summarize the present understanding of the Global Climate Change process have been already given in the Introduction. The specific forcing of BC and co-emitted species is the topic of an extremely comprehensive review by Bond and coworkers [75] which has been referenced in the more general work (i.e. including all the PM components) by Fuzzi and coworkers [59] later on. In the landscape of atmospheric aerosols, no other substance can be found in significant quantities with a MAC such high as the BC one [75], BC has very low chemical reactivity and its primary atmospheric removal process is wet or dry deposition to the surface. For this reasons, the analysis [75] mainly focuses on BC and the complex interplay with electromagnetic radiation and the atmospheric structure depicted in Fig. 4.

In quantifying the $\mathrm{BC}$ forcing, the review by Bond and coworkers adopts the estimates of the IPCC report of the year 2007 [76] to quote a total net forcing for BC ranging from 0.17 to $2.1 \mathrm{~W} \mathrm{~m}^{-2}$ (central value: $+1.1 \mathrm{~W} \mathrm{~m}^{-2}$ ). This results as the sum of direct (i.e. absorption and scattering of light and IR radiation) and indirect (basically phenomena related to cloud and snow-ice formation, see next subsection) effects. As usual in the IPCC evaluations, the forcing is calculated taking as reference the pre-industrial era i.e. the figure estimated for the year 1750. Even with a very large uncertainty, the $\mathrm{BC}$ net effect seems to remain always positive (that means: warming); actually, $\mathrm{BC}$ appears to be the second most important human emission after $\mathrm{CO}_{2}$ in terms of climate forcing. The picture becomes much more complicated and uncertain when the calculation is extended to include the effect of all the BC co-emitted species ( $\mathrm{SO}_{2}$ and $\mathrm{OC}$ in particular, $\mathrm{BC}$-rich emission considered only): such final evaluation gives a net forcing ranging from -1.45 to $+1.29 \mathrm{~m}^{-2}$ (central value: $-0.06 \mathrm{~W}$ $\mathrm{m}^{-2}$ ) and the lack of knowledge on the mechanisms of cloud interactions with both $\mathrm{BC}$ and co-emitted $\mathrm{OC}$ is considered to be the main term in the uncertainty budget. The interplay between $\mathrm{BC}$ and co-emitted species is further discussed in [77]: by a a multiple-mixing-state global aerosol micro-physics model, the Authors calculate that the $\mathrm{BC}$ direct forcing effect can vary by a factor $5-7$, depending on both the BC size distribution and mixing state. They claim that a more detailed representation of $\mathrm{BC}$ size distributions and mixing state is therefore required to assess the effectiveness of 


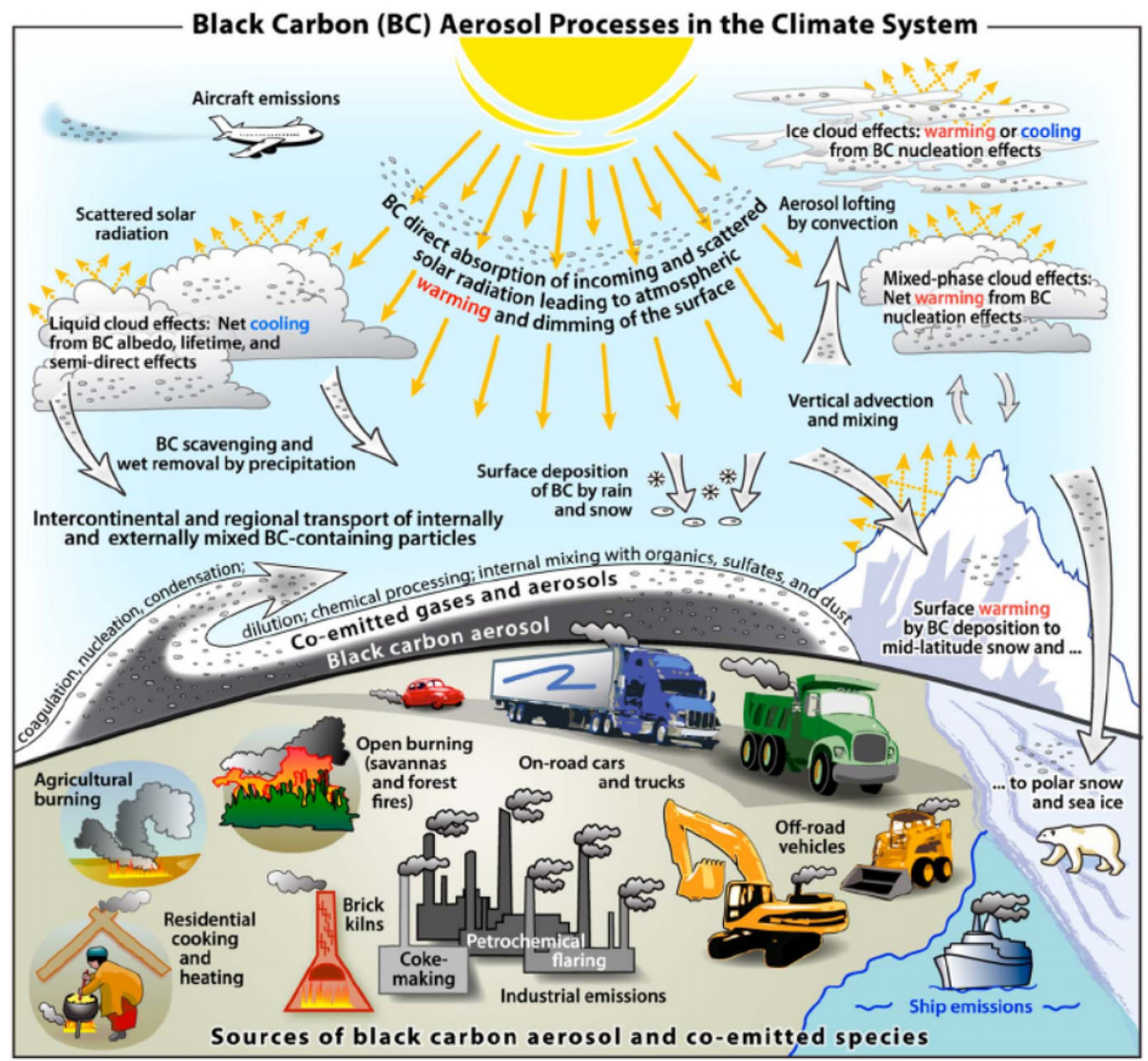

Fig. 4 Cartoon description of the BC climatic effect. Extracted from [75]

mitigation strategies and to avoid incorrect estimates of the BC climatic impact, reducing confidence in both the magnitude and sign of resulting future temperature changes. Furthermore, data on the BC spatial distribution (vertical, mainly) are still too poor to provide reliable inputs/constraints for the models. Effects of seasonal variation of BC concentration on local and regional climate, as the observed decreasing trend in monsoon rainfall over different regions in India, have been also discussed [78]. The picture is probably even more complicated since, as pointed out by Fuzzi and coworkers [59], the climatic role of $\mathrm{BrC}$ is basically still neglected in the models so far adopted and implemented. Finally, second order effects such as the change in air quality due to the warming or cooling of the atmosphere are also not accounted yet [79].

The role of bioaerosol as indirect climate forcing has been underlined in the Introduction. This is the result of a complex interaction with the total environment as reviewed in the work by Frhlich-Nowoisky et al. [80] and depicted in Fig. 5.

Since the first indications by Sands and coworkers [81], the role of biological particles in cloud formation (i.e. pollen, fungal spores, and bacteria can be activated as CCNs) precipitations, ecosystem interactions, has been the subject of an increasing number of studies fully quoted in [80] to which we refer. Steps toward a more realistic 


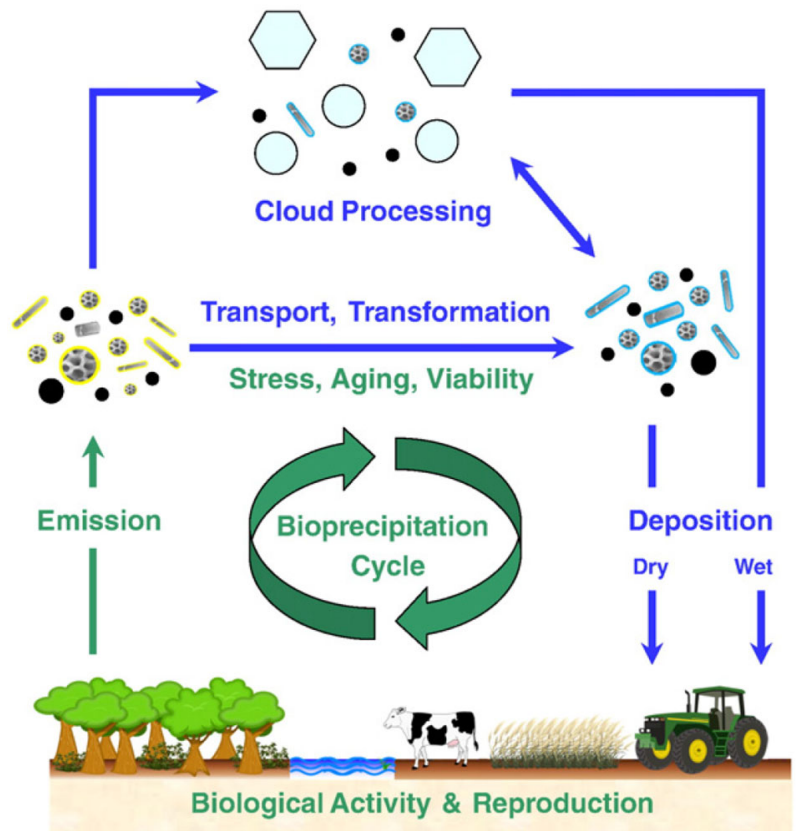

Fig. 5 Schematic of Bioaerosol cycling in the Earth system. Extracted from [80]

modelling of the effects of bioaerosols on climate at different scales (from local to global) will require a multidisciplinary effort addressing bio-particle identification and characterization; atmospheric transport and transformation (including viability changes); and interaction with the ecosystem.

\subsubsection{Ice darkening}

The effect of deposition/incorporation of carbonaceous aerosol, mainly BC or EC, on snow and ice is part of the wider theme discussed in the previous sub-section but deserves some separate comments. Here again, Bond and coworkers [75] collect most of the present understanding. The topic is double-fold: while the snow/ice darkening due to $\mathrm{BC}$ inclusion produces a global radiative forcing, the presence of carbonaceous aerosol favours the melting and speed up the glaciers retreat. The albedo of clean snow is quite high, around 0.9 and up to 0.999 for ice grains [75], and reduces to about 0.4 and 0.2 for melting and dirty snow, respectively [82]. Due to such a high albedo, even aerosol with relatively high single-scatter albedo (e.g., aerosol with high $\mathrm{OC}: \mathrm{BC}$ ratio), differently from their behaviour in the atmosphere, causes a positive radiative forcing. The mixing of CA and dust, due to long range transport, makes the amount of the albedo reduction highly variable, with the perturbation caused by BC becoming smaller with increasing dust burden [75]. The change in snow albedo and the consequent increase of solar light absorption speed up the snow aging process, resulting in an accelerated growth of the snow effective grain size. The 
albedo reduction due to $\mathrm{BC}$ increases with grain size [83] with a progressive an iterative climatic effect. Long-term observations of summer broadband albedo over the Greenland ice sheet found that summer albedo decreased at a rate of 0.02 decade $^{-1}$ between 1996 and 2012. [84]: the study indicates that the darkening is associated with higher temperatures and enhanced melting, which in turn causes the expansion and persistency of areas with exposed bare ice. Snow/ice melting caused by BC can therefore ends to anticipated exposure of the underlying surface which has a much lower albedo (around 0.2 for tundra or soil, [85]: this warms the surface and adjacent atmosphere, the so-called known "snow albedo feedback". Part of this feedback involves the increase of the cryoconite holes in glaciers [86]. Cryoconite is the dark, unconsolidated sediment that is found on the surface of glaciers worldwide [87], it is formed by the interaction between mineral particles and the microbial communities present on the surface of glaciers [88] and it also acts as accumulator of several anthropogenic species [89] and radioactive fallout [90]. Cryoconite has the potential to significantly impact surface albedo [86]. The cumulative global effect of BC incorporated in snow and ice is evaluated in the range $0.01-0.09 \mathrm{~W} \mathrm{~m}^{-2}$ (central value: $0.04 \mathrm{~W} \mathrm{~m}^{-2}$ ) [75]. The estimate suffers of several crucial approximations: the $\mathrm{BrC}$ effect is not included in any present calculation and the $\mathrm{BC}$ concentration data are far from be exhaustive. In the recent analysis by Khan and co-workers [91], the concentration of BC dissolved in ice/snow [92] is reported to vary from 0.62 to 170 $\mu \mathrm{gL}^{-1}$ in several high alpine regions of the Himalayas, Rocky Mountains, Andes, and Alps.

A complete discussion of snow/ice covering reduction falls outside the scope of this review: some results of measurements and models on particular regions and under different perspectives are given in [93-95]. A "rule of thumb" indicates that the average level of the snowline rises by roughly $150 \mathrm{~m}$ per Celsius degree [96]: present estimates consider an increase of 0.25 and 0.36 Celsius decade ${ }^{-1}$, respectively in the first and second half of the 21 st century [96] and this could result, at the end of the century, in the snow volume reduction reported in Fig. 6.

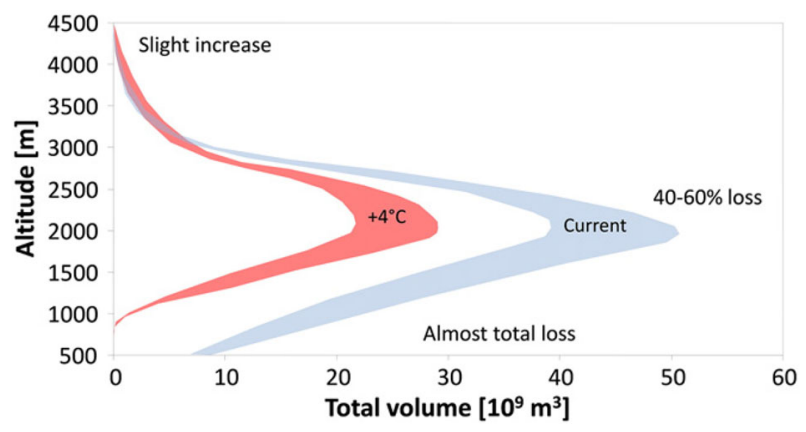

Fig. 6 Snow volume under current climate and a possible future climate with winters 4 Celsius warmer than today. Snow volume is computed as the average snow depth multiplied by the surface area on which it lies, for elevation levels between ranging from 200 to $4500 \mathrm{~m}$ in Switzerland. Extracted from [96] 


\subsubsection{Visibility degradation}

Visibility is defined by the World Meteorological Organization as the distance at which the contrast (C) of a given object with respect to its background is just equal to the contrast threshold of an observer [97]. A threshold contrast $\mathrm{C}=0.02$ is usually employed for visual range calculation [98]. A poor visibility (lower than $2 \mathrm{~km}$ according to [99]) can affect the transport systems, impacting in timing and safety, as well as the economical exploitation of touristic sites, as early recognized in the Grand Canyon area [100] in USA. Actually, the awareness of the negative impact of air pollution on visibility, see for example Fig. 7, triggered the USA-IMPROVE (Interagency Monitoring of Protected Visual Environments program) long-term program [102].

Since the 1952 "London Great Smog" event, when visibility reduced to a few meters, the degradation mechanism is attributed mainly to high concentrations of aerosol particles, with scattering effects being generally dominant on absorption [103]. Meteorological conditions, relative humidity in particular, are also determinant on visibility.

Fine particles (i.e. the PM2.5 fraction) are most effective in scattering the visible light: the maximum scattering cross section per unit mass, per several materials present in the atmospheric aerosols, falls in the range $0.7 \lambda<D<2.2 \lambda$, where $\mathrm{D}$ is the diameter of spherical aerosol (or the aerodynamic diameter of an irregular particle and $\lambda$ is the wavelength of the incident light [98]). Considering the solar light spectrum [104], the latter behaviour makes particle in the dimensional range $0.1 \mu \mathrm{m}<\mathrm{D}<1 \mu \mathrm{m}$ particularly effective in scattering solar light. CA fall in such dimensional range [98]:

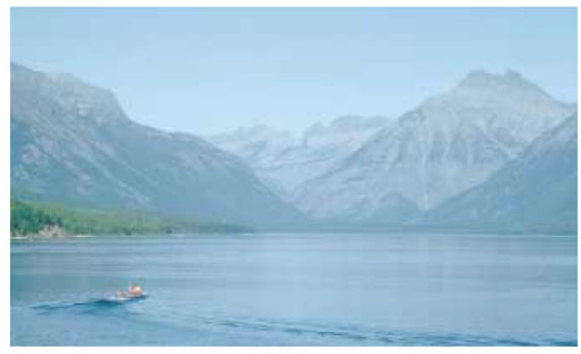

(a)

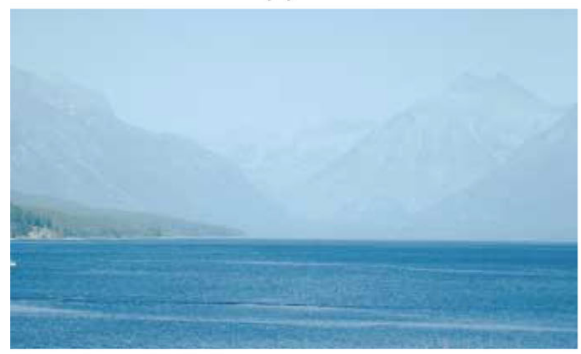

(c)

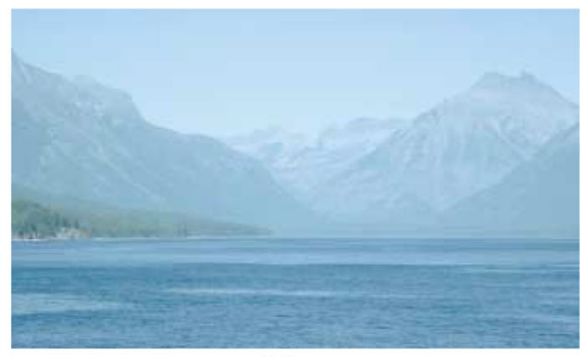

(b)

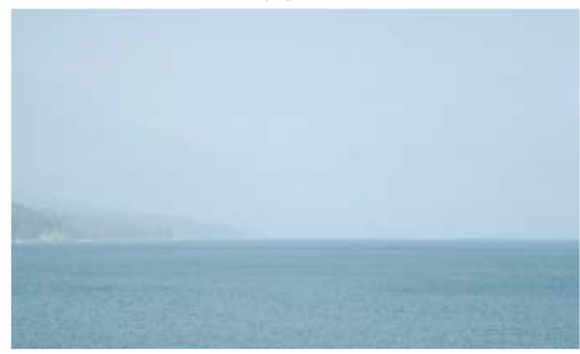

(d)

Fig. 7 The iconic picture showing the effect of haze on a Glacier National Park (Montana, USA) vista. Atmospheric fine PM concentrations associated with photographs are a 7.6, b 12, c 21.7, and d $65.3 \mu \mathrm{gm}^{-3}$. Extracted from [101] 


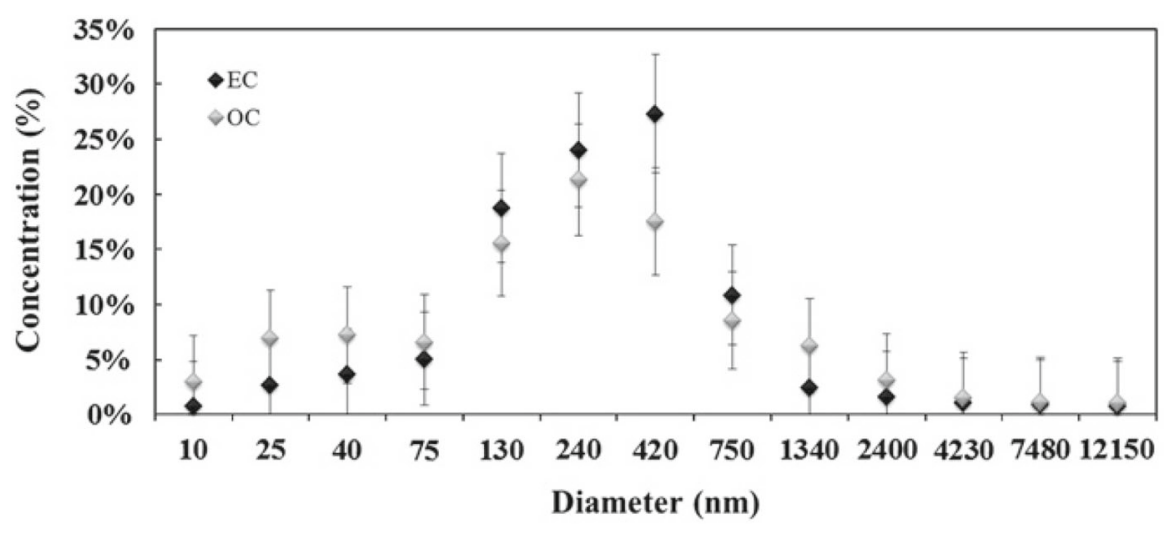

Fig. 8 OC and EC size distribution measured in a PM10 sample collected in a urban background site in Milan, Italy. Extracted from [105]

a typical size distribution for EC and OC collected in an urban site is shown in Fig. 8. Therefore $\mathrm{CA}$ extinguish light both by scattering and absorption (BC and $\mathrm{BrC}$ at short wavelengths: in rural areas absorption accounts for 5-10\% of total extinction; in urban areas, EC accounts for 20-30\% of total extinction [106]) and have been proven to be major contributors to visibility degradation in several studies ( [107-109] and references therein).

\subsubsection{Cultural heritage deterioration}

The anthropogenic impact on cultural heritage conservation/deterioration has been always heavy and multi-fold: since the beginning of the industrial era, the economic evolution has worsened environmental conditions, giving rise to progressively alteration and degradation processes. Such negative effect is concentrated in urban areas where open air monument and materials are directly and continuously exposed to atmospheric pollutants, as those emitted by combustion processes, which cause aesthetic and material damages [110]. Such damages are usually referred as "black crusts": an example is given in Fig. 9.

Sulphur di-oxide has been first indicated as a deleterious pollutant for stone monuments in the open air [111] but the composition of atmospheric pollution has progressively changed and carbonaceous particles, mainly from fossil fuel combustion, have more and more become a main cause of material damages in the urban areas ([112] and references therein). A quite complete chemical characterization of the "black crusts" composition in several open air European monuments [112] resulted in a TC content of about $1.5-7.5 \%$ with an OC:EC ratio ranging from 0.5 to 8.5. OC:EC ratios turned out related to the age of black crusts, with higher OC:EC ratios corresponding to more recent damage layers [112]. Atmospheric pollution and carbonaceous aerosol affect the cultural heritage in indoor or semi-confined environments [113,114]. Figure 10 reports the concentration of carbonaceous compounds measured in five samples collected in the Michelozzo's Courtyard in Florence (Italy) [115]: values are very similar to those retrieved in open air materials [112]. 


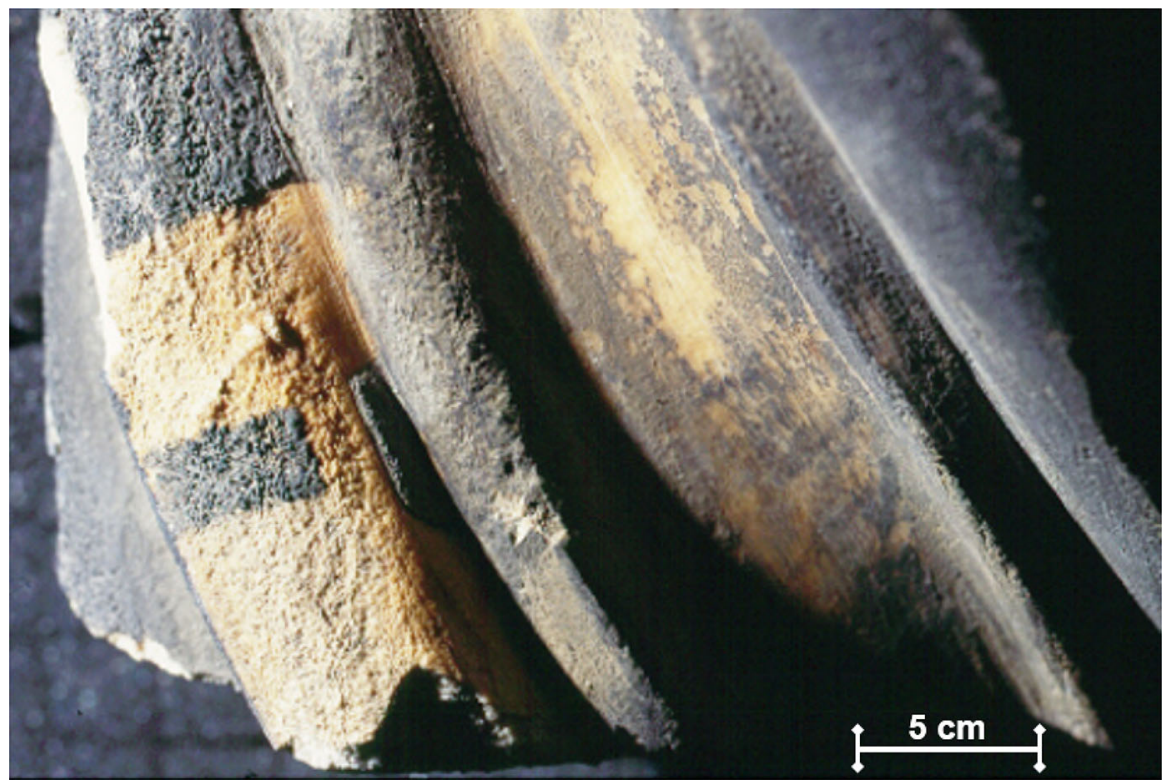

Fig. 9 Image by Scanning Electron Microscopy of a stratigraphic section of a marble sample extracted from a mullioned window in the Santa Maria del Fiore Cathedral (Florence, Italy). The black crust, with a thickness of about $1 \mathrm{~mm}$, is evident in the left part of the picture where some zones have been cleaned by laser ablation. Courtesy of A. Zucchiatti

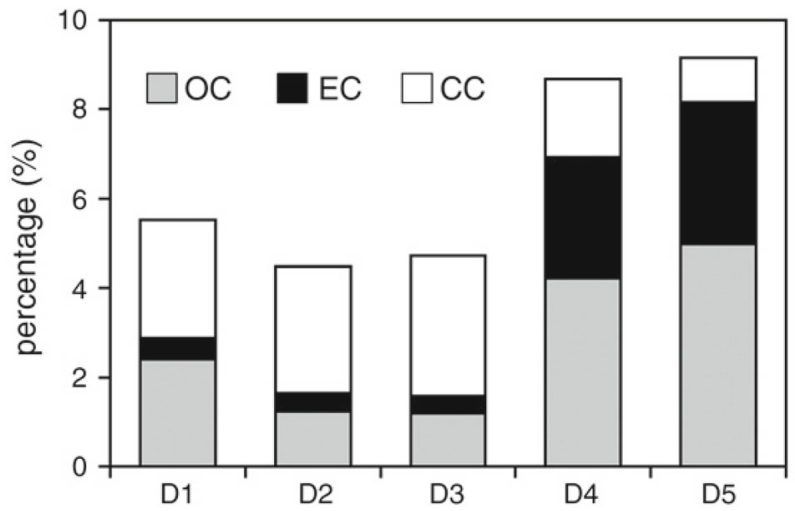

Fig. 10 Percentages of carbonate carbon (CC), OC and EC in five samples collected on horizontal surfaces inside the Michelozzo's Courtyard in Florence. Extracted from [115]

\subsection{Role in the source apportionment exercise}

Even the short discussion in the previous sub-sections highlighted the outstanding and polyhedric role of CA in the sanitary and environmental frame. This is true not only from a merely scientific point of view but for the economical and social consequences too. Any action and/or policy to mitigate the adverse effects of the atmospheric pol- 


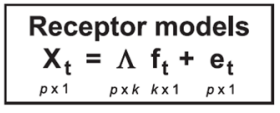

Knowledge required about pollution sources

prior to receptor modelling

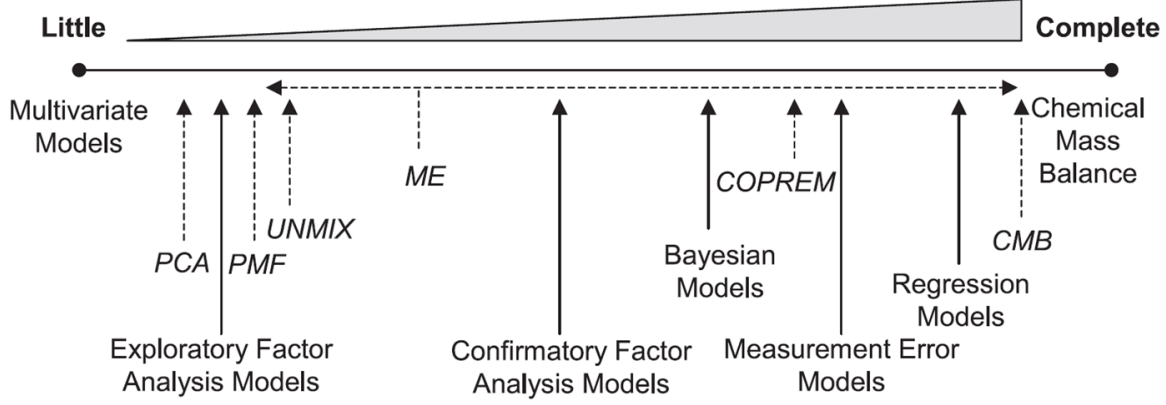

Fig. 11 Approaches to source apportionment using receptor models. Specific models are shown in italics and with dotted arrows. Extracted from [116]

lutants has to start from the knowledge of the emission sources. We use here the term "source" as shortcut to refer to any chemical/physical process, natural or anthropogenic, which introduces pollutants in an environmental matrix, in this case the Earth atmosphere. The procedure to single out and quantify the impact (i.e. concentration in the atmosphere) of the pollution sources in the air quality of a specific site and/or area is known as "source apportionment" ([116] and references therein). Such exercise can be based on emission inventories coupled with dispersion models to simulate aerosol emission, formation and transport [117] or on the statistical evaluation of PM composition data measured at receptor sites (receptor models [118,119]). The basics of receptor modelling is the conservation law for total mass and single PM species and thus a mass balance analysis can be used to identify and apportion the PM sources. From such simple assumption, a wide family of mathematical approaches has been developed as sketched in Fig. 11. Roughly, the solution of the mass balance equation can be obtained starting from a (supposed) knowledge of the number ad emission profile of the PM sources (i.e. adopting the Chemical Mass Balance algorithm, Figs. 11 and [118]) or by multivariate models with none (e.g. Principal Component Analysis, PCA [118]) or little assumptions (e.g. Positive Matrix Factorization, PMF [119]). A number of intermediate approaches have been also developed (Fig. 11 and [116]) and a full discussion is outside the scope of the present review: an European initiative implemented a wide and collective effort to assess best practices and quality assurance in the use of receptor and dispersion models [120,121].

Whatever is the model/approach to receptor modelling and source apportionment, the information on the presence of carbonaceous species in the emission profiles is always important and, in some cases, decisive to identify/disentangle specific sources. The quantification of OC and EC is quite common (see Sect. 4) and the OC:EC concentration ratio is often used as a distinguish feature of industrial or traffic-related processes. Database of emission profiles have been first build in USA [122] and more 
recently in Europe [123]. Carbonaceous compounds (OC, EC, BrC, single organic compounds, etc.) are usually present in (incomplete and sample list): various kinds of traffic exhausts [124], re-suspended dust [125], ships [126] and aircrafts [127] plumes [126], industrial processes [128], power plants [129] and biomass burning [130]. Most advanced receptor models, as the Multi-linear Engine, ME [131] (see Fig. 12), have made recently possible the merging/use in the source profiles of concentration/composition data together with optical properties of CA, as the trend of absorbance versus the light wavelength [132].

\section{Experimental approaches to the characterization of carbonaceous aerosol}

The large variety of compounds, effects, impacts and finally scientific disciplines related to the $\mathrm{CA}$ corresponds to a wide range of techniques and methods so far developed to monitor their concentration in the atmosphere, sources, composition and temporal evolution. Besides the intrinsic and unavoidable complexity, the present situation is partially confused and shows some paradoxes. While the European Directive 2008/50 imposes the measurement of OC and EC concentration in particular sites, the scientific community is still looking for a shared assessment of a suitable experimental methodology to accomplish the task. Optical equipment provide on-line BC monitoring in many part of the world even if it is well known that most of them are affected by severe artifacts. Furthermore, EC or BC are often considered as a possible new entry in the list of atmospheric pollutants to be subjected to concentration limits, but a standard material to use as reference for quality assurance is not available. Biomass burning is one of the major source of CA (and sometimes of PM) in several parts of the world but a clear definition and hence a detection method for $\mathrm{BrC}$ is not available yet. Actually, all the experimental methods to quantify carbon species (not including the search of specific molecules through a chemical analysis) suffer of a fundamental problem: there is no real net boundary but instead a continuous decrease of thermo-chemical refractiveness and specific optical absorption going from graphite-like structures to non-refractive and colorless organic compounds, respectively [133] (Fig. 13). Both BC and EC consist of the carbon content of the graphite-like material usually contained in soot and other combustion aerosol particles, which can be pictured as more or less disordered stacks of graphene layers or large polycyclic aromatics [134] [135].

In the next subsections, the main approaches and the state of the art to the identification and quantification of CA are discussed grouping in categories the jungle of techniques in the literature and in the market. We focus on the widespread, continuously-evolving, optical and thermo-optical approaches and we touch as well other connected or emerging techniques (for instance: reference methodologies adopted for calibration or validation purposes). Other extremely diffused methods, as aerosol mass spectrometry [136], standard chemical analyses and microbiology techniques, are not included in the discussion. 
(a)
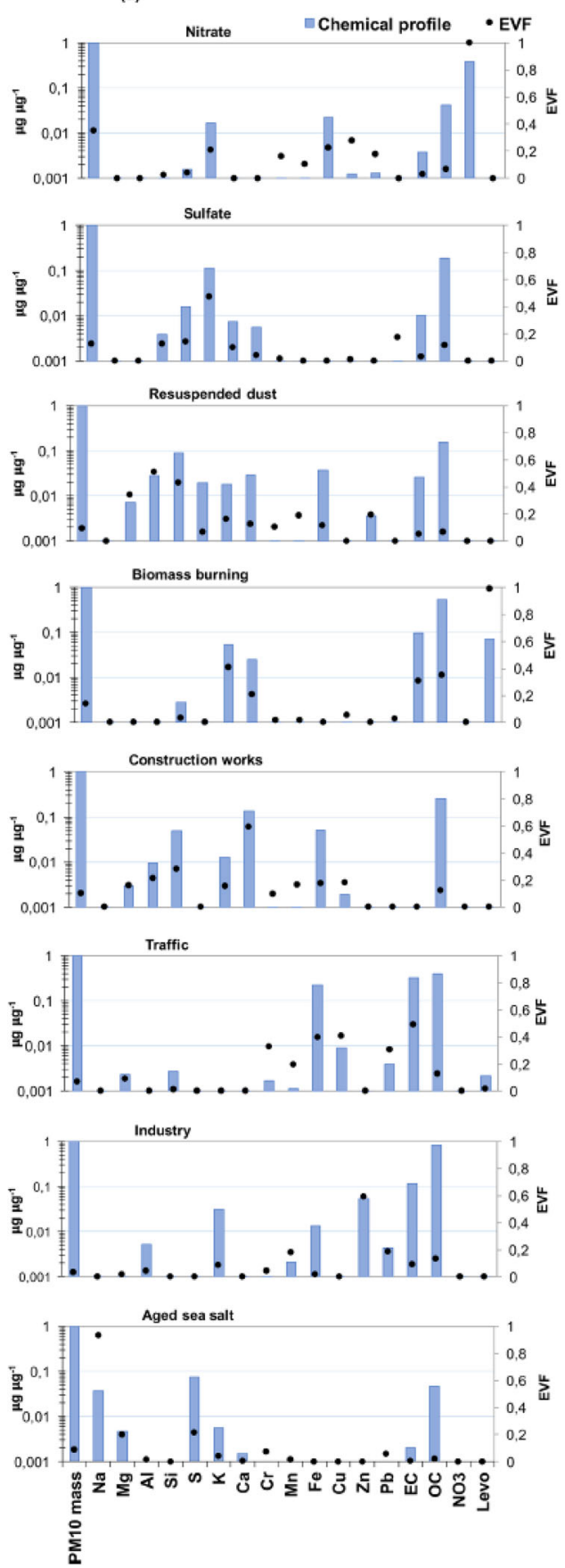

(b)
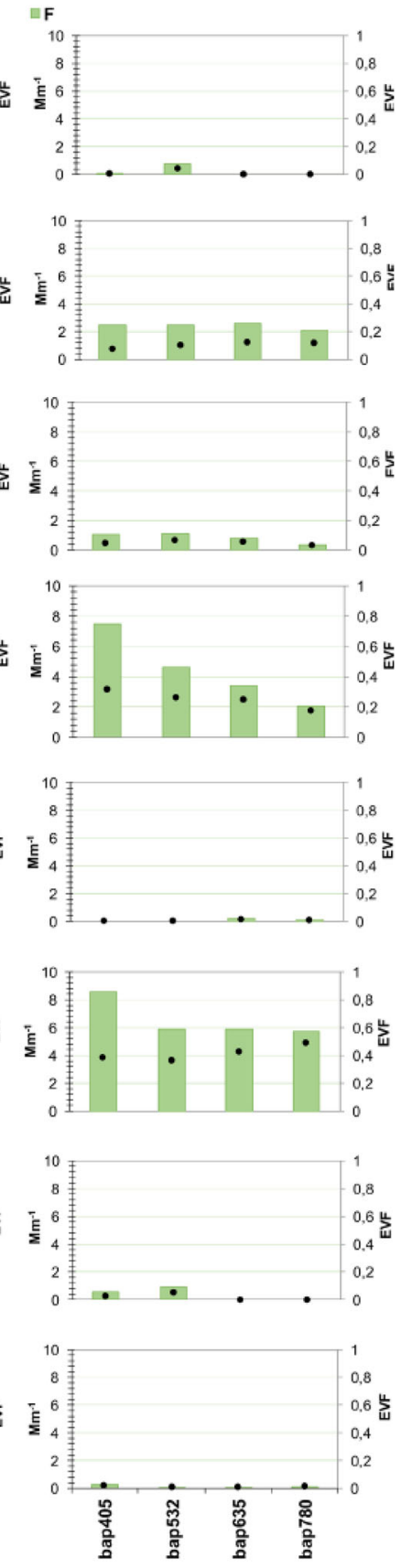

Fig. 12 a Chemical profiles of the PM10 sources identified by ME in a urban background site in Milan (Italy); b Corresponding apportionment of the PM absorbance $b_{a p}$ at $\lambda=405,532,635,780 \mathrm{~nm}$ of the eight-factor constrained solution. Bars represent the profiles and the black dots the Evaluation Factors. Extracted from [132] 


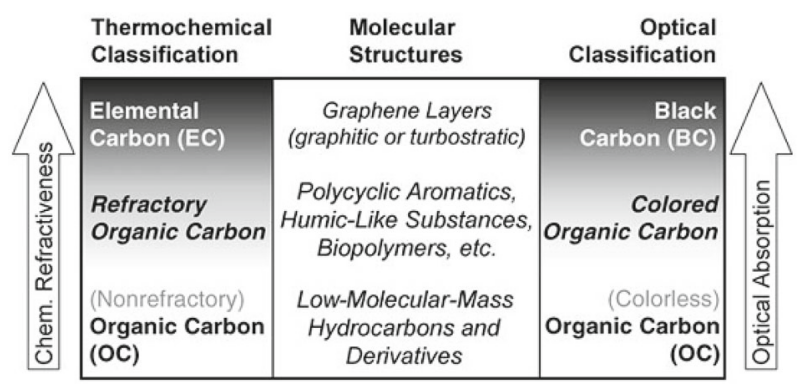

Fig. 13 Optical and thermo-chemical classification and molecular structures of black carbon (BC), elemental carbon (EC), and organic carbon (OC = TC - BC or TC - EC). Depending on the method of analysis, different amounts of carbon from refractory and colored organic compounds are included in OC and BC or EC. Extracted from [133]

\subsection{Optical determination of $\mathrm{BC}$ and $\mathrm{BrC}$}

The optical characterization of CA is probably the most used approach. It is based on the high absorption cross section shown by $\mathrm{BC}, \mathrm{EC}$ and partially $\mathrm{BrC}$, in a large range of wavelengths from IR to UV. Such feature can be exploited both for in-situ measurements and for on-line or off-line analyses of the PM collected on sampling filters or inertial impactor frames. The review article [45] gives a complete description of the topic and of the background theories on light scattering and absorption by small particles, but obviously does not include achievements and progresses of the last decade.

The quasi real-time direct measurement of aerosol optical extinction is at the basis of the Aethalometer [17], one the most diffused instruments worldwide. Optical extinction can be defined as the removal of light from a beam due to aerosol scattering and absorption. Absorbed energy is then converted into thermal energy thus heating the absorbing particles and their surroundings. With the Aethalometer, PM is continuously accumulated on a quartz fibre filter tape: the deposit is illuminated by a light beam at one or more wavelengths (up to seven in the most recent models, with $\lambda=370-950$ $\mathrm{nm}$, see https://mageesci.com/) and the light transmitted beyond the filter is collected by a suitable photodiode. When the deposition thickness causes a fixed (maximum) extinction, the filter steps forward and the deposit continues in a new position. In such simple set-up, the light extinction (or attenuation, ATN) is adopted as a proxy of the absorption, ABS, and it is continuously measured by the Lambert-Beer's law:

$$
\mathrm{ATN}=\ln \frac{I(0)}{I}
$$

where $\mathrm{I}(0)$ is the intensity of the light beam sent to the sample (the loaded filter tape) and $\mathrm{I}$ is the intensity of the transmitted light measured by the photodiode. During operation, from time $t$ to time $t+\Delta t$, the column of aerosol-laden sample air will deposit particles to the filter, resulting in an increase of ATN. According to the Lambert-Beers law (Eq. 1), the aerosol attenuation coefficient of the aerosol particles collected on the filter, $\mathrm{b}_{A T N}$, is defined as: 


$$
\mathrm{b}_{A T N}=\frac{\Delta \mathrm{ATN}}{\Delta \mathrm{t}} \frac{A}{V}
$$

where $\mathrm{A}$ is the area of the sample spot to which particles are deposited, $\mathrm{V}$ the volumetric flow rate and $\triangle \mathrm{ATN}$ is the change in attenuation during the time interval $\Delta \mathrm{t}$. BC mass concentration can be obtained by the equation:

$$
B C=\frac{\mathrm{b}_{A T N}}{\sigma_{A T N}}
$$

In the Aethalometer, $\sigma_{A T N}$ is defined as the specific attenuation cross-section for the $\mathrm{BC}$ deposit on the filter. A default value for this parameter is empirically fixed by the manufacturer (but the user can set a different value) and is expressed as:

$$
\sigma_{A T N}=\frac{14625}{\lambda}
$$

Despite the simplicity of the Aethalometer approach, the $\mathrm{b}_{A T N}$ value may differ from the true $\mathrm{BC}$ absorption coefficient, $\mathrm{b}_{A B S}$, since the light extinction can be significantly and even predominantly determined by the scattering too, summing up the effect of all PM and not of CA only. Therefore, the Aethalometer approximation produces significant uncertainties in the assessment of BC concentration values. Several algorithms have been proposed to correct the Aethalometer data, taking into account the diffusive component of the PM collected on the filter tape, the filter-matrix effect and the filter loading [137-142]. In these works, two calibration factors (C and R(ATN)) are generally introduced: they can be used to convert Aethalometer attenuation measurements to absorption coefficients:

$$
\mathrm{b}_{a b s}=\mathrm{b}_{A T N} \frac{1}{\mathrm{C} \mathrm{R}(\mathrm{ATN})}
$$

where $\mathrm{C}$ and $\mathrm{R}(\mathrm{ATN})$ describe the two effects which change the optical properties of filter embedded particles, with respect to the properties of the same particles in the airborne state. The first effect is responsible for $\mathrm{C}$ being greater than unity and is caused by multiple scattering of the light beam at the filter fibres in the unloaded filter. This leads to an enhancement of the optical path and thus to enhanced light absorption of the deposited particles [143]. Any other effect caused by deposited particles is described by the empirical function R(ATN) which varies with (a) the amount of aerosol particles embedded in the filter and (b) optical properties of the deposited particles. For unloaded filters $\mathrm{R}$ is set to unity, i.e. $R(A T N=0)=1$. With the gradual increase in attenuation due to the accumulating particles in the filter, the absorbing particles capture a higher fraction of the scattered light which leads to a reduction of the optical path in the filter $(R<1)$. As a consequence, generally lower attenuation coefficients are measured for higher filter loading than for lightly loaded filters. This is named as "shadowing effect", even if this term is a somewhat misleading description as sub-micrometer particles do not visibly cast shadows. If light scattering particles are embedded in the filter matrix, the shadowing effect may be partially reduced and R(ATN) may exhibit a smaller decrease with increasing loading of the filter. This phenomenon is due to additional light scattering arising from the transparent aerosol material. The value 
of R(ATN) will thus also depend on the single scattering albedo $\omega_{0}$ of the sampled aerosol, which is defined as:

$$
\omega_{0}=\frac{\mathrm{b}_{s}}{\mathrm{~b}_{a b s}+\mathrm{b}_{s}}
$$

where $\mathrm{b}_{s}$ and $\mathrm{b}_{a b s}$ are the aerosol light scattering and absorption coefficients, respectively. For the derivation of $\mathrm{b}_{a b s}$, the exact knowledge of the empirical calibration values $\mathrm{C}$ and $\mathrm{R}$ is of course of great importance. The evaluation of these two values is, in general, site-dependent and requires the knowledge of other parameters like the scattering properties of the aerosol and the aging of the particles, both very difficult to produce/evaluate. Without these corrections, the Aethalometer approach is quite reliable only for thin aerosol layers with a high black carbon mass fraction $(>10 \%)$ and a low scattering coefficient of the particles $\left(\approx 1000 \mathrm{~cm}^{-1}\right)$. These conditions are usually met for samples of an urban aerosol, but they are no longer valid for background aerosols [50].

The Aethalometer limitations have been almost overcome by the development of the Multi-Angle Absorption Photometer (MAAP) [50]. This instrument can provide high temporal resolution $\mathrm{BC}$ data measuring the light absorption $(\lambda=670 \mathrm{~nm})$ of particles sampled on a quartz filter tape and converting it to $\mathrm{BC}$ concentration by the relationship $\mathrm{BC}=\mathrm{b}_{a b s} \sigma_{a b s}$ (the value of the aerosol mass cross-section, $\sigma_{a b s}$, is set by the manufacturer at $6.6 \mathrm{~m}^{2} \mathrm{~g}^{-1}$ ). The MAAP is based on the simultaneous measurement of radiation penetrating through and scattered back from a particleloaded fiber filter (see Fig. 14).

In the MAAP set-up, the light penetrated through a particle-loaded fiber filter is completely diffused and its angular distribution in the forward hemisphere can be parameterized by a $\cos (\theta)$ relationship, with $\theta$ being the scattering angle relative to the direction of the incident radiation. The back-scattered radiation contains a diffusely scattered fraction proportional to $\cos (\theta-\pi)$, and a fraction that is best parameterized by a Gauss law proportional to $\exp \left[-(1 / 2)(\theta-\pi)^{2} / \rho^{2}\right]$, with $\rho$ being a parameter measuring the surface roughness of the aerosol layer deposited on the filter. The Gaussian-distributed fraction of the back-scattered radiation can be taken as radiation reflected from a rough surface. The partitioning of back-scattered radiation between diffused and Gaussian type depends on the sampled aerosol. The measurement of the radiation passing through the filter at the scattering angle $\theta=0^{\circ}$, and the simultaneous measurement of the radiation scattered back from the filter at two detection angles $\theta=130^{\circ}$, and $\theta=165^{\circ}$, permit the full determination of the irradiance in the forward and back hemisphere relative to the incident light beam. The exact position of the detection angles was chosen such that the partitioning between diffused and Gaussian types can be determined with highest resolution. In the MAAP, the determination of the aerosol absorption coefficient $\mathrm{b}_{a b s}$ of the deposited aerosol uses radiative transfer techniques. The particle-loaded filter is treated as a two-layer system: the aerosolloaded layer of the filter and the particle-free filter matrix. Radiative processes inside the layer of deposited aerosol and between this layer and the particle-free filter matrix are taken separately into account. In this approach, originally developed by [144] and modified for this purpose by [50], multiple reflections between the aerosol-loaded filter layer and the particle-free filter matrix are treated by the adding method [145]. Starting 


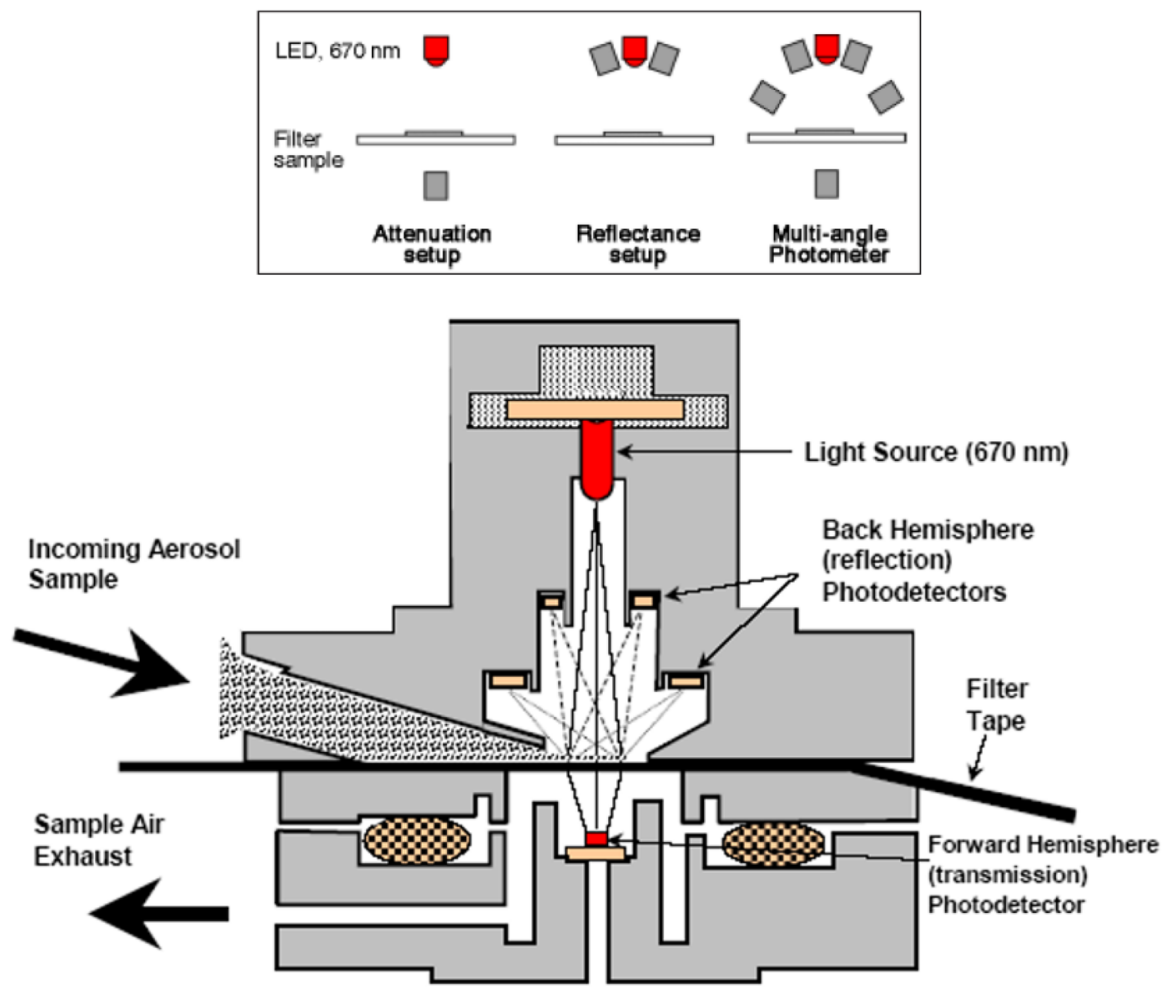

Fig. 14 Schematic of the multi-angle absorption photometry technique. Top: schematic set up for attenuation (i.e. Aethalometer like) and reflectivity measurements compared to the multi-angle photometer set up. Bottom: layout of the MAAP sensor unit, extracted from [52]

from quantities directly measurable, the model resolution gives the two parameters needed to calculate the absorbance ABS (fraction of light absorbed in the filter sample):

$$
A B S=(1-S S A) \tau
$$

where $\tau$ is the total optical depth of the loaded aerosol-filter layer. The $\mathrm{b}_{a b s}$ value is therefore calculated by the simple relation:

$$
b_{a b s}=\operatorname{ABS} \frac{A}{V}
$$

where $\mathrm{A}$ is the area of the sample spot to which particles are deposited, $\mathrm{V}$ is the volume of the air mass flowed through the filter.

The figure $\sigma_{a b s}=6.6 \mathrm{~m}^{2} \mathrm{~g}^{-1}$ has been set by the MAAP developers after some comparisons between MAAP absorption data and EC values provided by a $\mathrm{BC}$-sensitive thermal technique, with artificial and ambient aerosol samples [50]. However, many works report $\sigma_{a b s}$ values ranging between 4 and $25 \mathrm{~m}^{2} \mathrm{~g}^{-1}$ at $\lambda \approx 650 \mathrm{~nm}$ ([4] and references therein; [35]). This large variety of $\sigma_{a b s}$ values suggests that the aerosol 


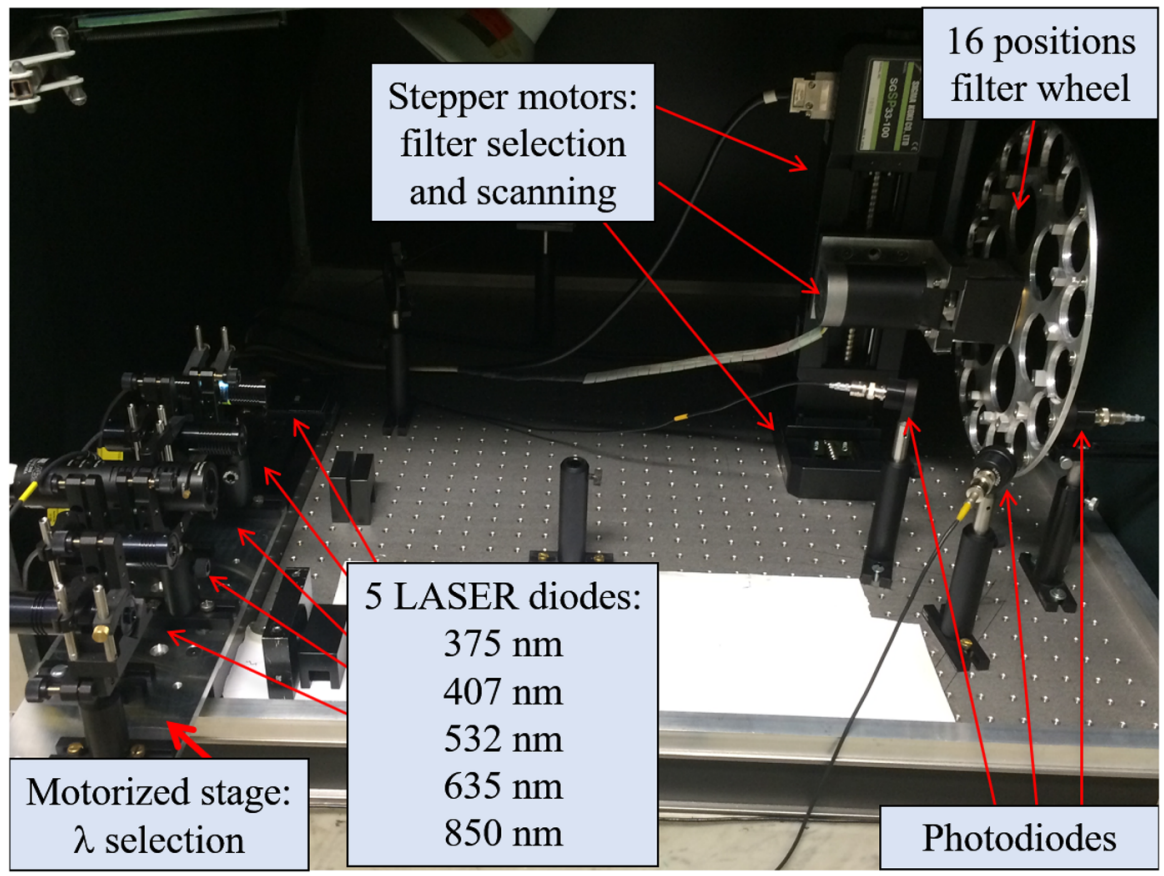

Fig. 15 The MWAA set-up

mass cross-section depends on the composition and the aging of the particles. For this reason, it is important to note that, in general terms, absorption can not be a proxy for light-absorbing carbon mass [4]. The assumption that there is a constant ratio between absorption and $\mathrm{BC}$ concentration is strictly valid only when the particles to be measured have the same optical properties of the particle used to determine this ratio: nevertheless a proportional relationship is often adopted for practical and monitoring purposes.

While the MAAP approach makes a step forward since provides a quasi-direct measurement of the PM absorbance without the need of situ-specific corrections, the instrument utilizes a sole wavelength. With respect to the Aethalometer, the possibility to determine the dependence of the absorption properties on the wavelength of the incident light has been thus lost. As a consequence, the MAAP can provide information on $\mathrm{BC}$ only while the possible $\mathrm{BrC}$ content in the sampled PM remains unrevealed or even causes artifacts (since it can contribute to the sample absorption at $\lambda \approx 650 \mathrm{~nm}$, which remains entirely attributed to BC in the MAAP analysis).

The MAAP approach has been extended by the Multi-Wavelength Absorption Analyzer (MWAA) [105,146] to off-line analysis of PM samples collected on media of variable dimension and composition. In the MWAA (Fig. 15) light is emitted by low-power laser diodes $(\lambda=375,405,532,635,850 \mathrm{~nm})$, automatically aligned by mechanical benchmarks and sequentially sent to the sample.

Samples in analysis, up to sixteen, are arranged in an aluminium wheel mounted on the shaft of a stepping motor, which automatically changes the samples. The stepping 


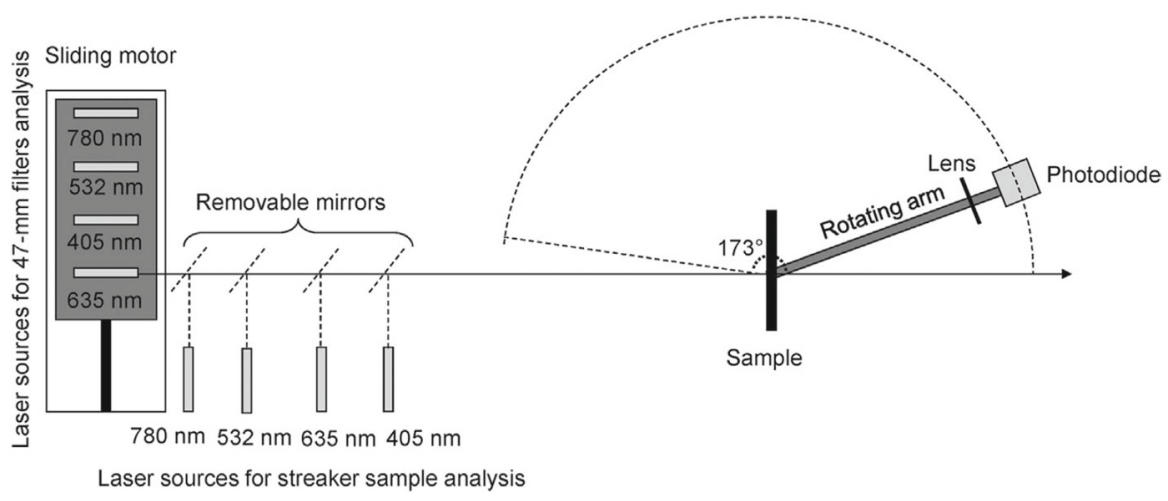

Fig. 16 Scheme of the polar photometer developed at the University of Milan. The photodiode rotates horizontally in the scattering plane. Extracted from [154]

motor is mounted on an $\mathrm{x}-\mathrm{z}$ platform, which is moved by two linear translators to scan the surface of the sample under analysis. PM samples routinely collected for air quality monitoring have homogeneous deposit, however inhomogeneous collecting media can be easily mounted and analyzed with proper adapters. The laser beam is collimated to hit a filter portion of about $1 \mathrm{~mm}^{2}$ : the use of a collimated beam requires a scanning of the filter surface to obtain a representative average value but gives the possibility to exploit the same set-up with filters where the PM deposit covers small areas (e.g. multistage impaction plates [105] or streaker frames [147]). Transmitted and scattered light is collected by three photodiodes positioned at the same angles of the MAAP set-up (i.e. at $\theta=0^{\circ}, 125^{\circ}$ and $135^{\circ}$ ). A fourth photodiode receives from a beam splitter a constant fraction of the laser beam and it is used, together with reference samples, to monitor the lasers stability. Actually, measurements on the same filter before (blank) and after (loaded) the sampling are performed in different moments and must be normalized to the same beam intensity. The MWAA can also provide off-line analyses of the MAAP an Aethalometer tapes and actually it has been used several times as multi-wavelength reference in conjunction with such instruments [142,148-151] or to retrieve the $\mathrm{BC}$ concentration in PM samples collected on polytetrafluoroethylene (PTFE) filters [152].

Both the MAAP and the MWAA measure the angular distribution of the light scattered from the sample under analysis relying on a limited number of photodiodes positioned at fixed angles. However, the simplicity of this solution could be payed in term of larger uncertainties when the light distribution differs significantly from the assumptions. This limitation is overcome by polar photometers $[153,154]$ where just one photodiode is mounted on a movable arm. The detector rotates around the sample (Fig. 16) providing a direct and almost continuous measurement of the angular distribution of scattered light. The polar photometer approach is less model-dependent of the MWAA but requires longer analysis times. 


\subsection{Thermo-optical determination of $\mathrm{OC}, \mathrm{EC}$ and $\mathrm{BrC}$}

Heating-based methods $[49,155,156]$ are presently the most widespread approach to quantify total carbon (TC) and its main fractions, OC and EC. These methods necessarily require the collection of PM on suitable supports, able to resist to the high temperatures reached during the analysis $\left(>800^{\circ} \mathrm{C}\right)$ : such constrain effectively limits substrate choice to quartz fiber filters only. These filters are not as performing as the PTFE or polycarbonate membranes for elemental/chemical analyses (due to their thickness, composition and internal contamination) so that, in campaigns where both EC/OC and elements/ions concentration values are required, two side-by-side samplers collecting PM on quartz fiber filters and on other media with low blank values are often necessary. It is worthy to note that problems induced by positive and negative artifacts can arise when comparing PM -and fractions contained thereincollected on different filtering media [157]. Quantification of TC is generally an easy task, carried out by measuring the total $\mathrm{CO}_{2}$ evolved when burning a small piece of the filter sample. The relative simplicity in quantifying $\mathrm{TC}$ is counterbalanced by a very tricky discrimination of EC and OC which Separation is based on several assumptions. First EC is considered refractory and does not volatilize under about $550^{\circ} \mathrm{C}$, whereas OC can be progressively volatilized by heating starting from about $150^{\circ} \mathrm{C}$. Therefore, thermal methods based on refractiveness (see Fig. 13) foresee two heating ramps (see Fig. 17): during the first one, the sample is kept in an inert atmosphere (usually pure $\mathrm{He}$ ) where OC only is supposed to volatilize; in the second ramp, EC is progressively burnt over time keeping the sample in a oxidizing atmosphere.

In most of the cases, this simple scheme is not sufficient to correctly separate the two fractions. In fact, during the first ramp, part of the OC can actually evolve to a new form of carbon, known as pyrolytic carbon ( $\mathrm{PyrC})$ : this compound has optical and refractory properties very similar to those of EC [159]. Pyrolysis consists in the conversion of an organic compound by thermal energy into one or more different compounds, and it mainly occurs in inert environments (lack of oxygen or presence of catalysts and, above all, for particular materials like tobacco smoke, pollen). In this condition, PyrC cannot evolve in the inert atmosphere anymore, leading to an underestimation of OC and an overestimation of $\mathrm{EC}$, if the two fractions are quantified just considering CA evolved in $\mathrm{CO}_{2}$ along the two thermal ramps and without any further correction. This effect can be enhanced by particular compounds: typically alkali metals and some kind of oxides can act as catalysts, favouring charring [160]. A similar effect can occur if PM contains organic compounds prone to PyrC formation, such as volatile organic compounds (VOCs). Pyrolysis leads to the variation of the optical properties of the sample as PyrC is strongly light absorbing; thus, in thermo-optical analyses, the optical transmission (TOT) or reflectance (TOR) of a laser through/by the filter is continuously monitored [155,161]. Due to pyrolysis, the transmittance/reflectance of the filter decreases during the first part of the analysis, somehow proportionally to PyrC mass formation. When oxygen is injected into the line at the beginning of the second ramp, the remaining carbon (EC originally present in the sample + PyrC derived from $\mathrm{OC}$ pyrolysis) starts to burn, causing a progressive increasing of the laser transmission/reflection signal. When the filter transmittance (or reflectance) signal 


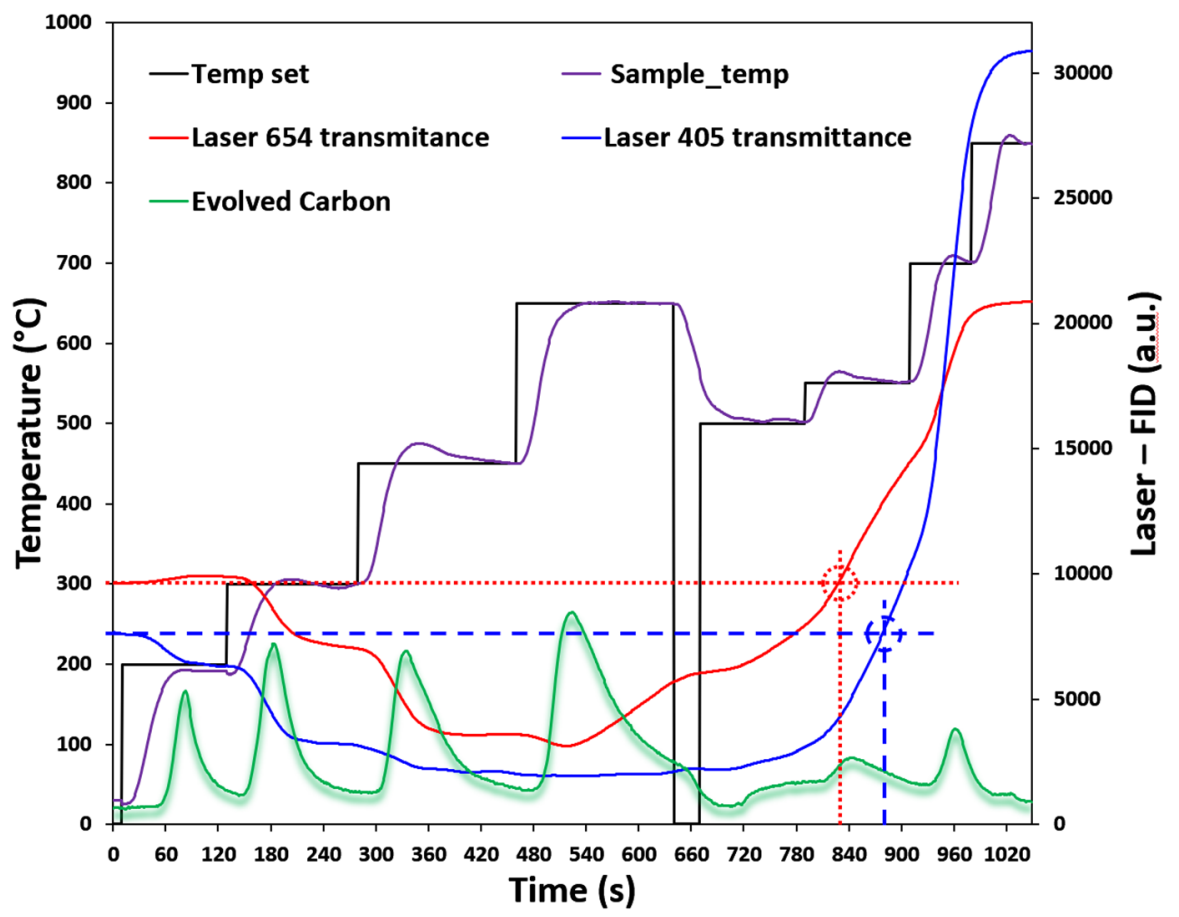

Fig. 17 TOT analysis following the EUSAAR_2 protocol [48]: first the sample undergoes a heating ramp up to about $650 \mathrm{~s}$ (inert atmosphere), while, after a partial cooling, a second ramp follows from about $670 \mathrm{~s}$ to the end of the cycle (10\% oxygen atmosphere). The shown analysis has been performed by a home-modified Sunset ${ }^{\circledR O C} / E C$ analyzer [158], subsequently at two different wavelengths, $\lambda=654 \mathrm{~nm}$ and $405 \mathrm{~nm}$ (red and blue lines, respectively). Note the two positions of the split time individuated at each wavelength (dotted circles) which differ for more than $30 \mathrm{~s}$ : EC determined @ $\lambda=405 \mathrm{~nm}$ turns out to be about $70 \%$ of EC determined @ $\lambda 654 \mathrm{~nm}$. The example clarify the slippery meaning of the "operative" OC and EC definitions, since their quantification is largely dependent on the features of the thermo-optical analysis, including the wavelength of the light source and the parameters (temperature steps, plateau times) of the thermal ramps

comes back to the value measured at the beginning of the analysis, the operative methodology assumes that a quantity of refractory carbon $(\mathrm{EC} / \mathrm{PyrC})$ equal to the one formed by pyrolysis is burnt. The CA evolved in $\mathrm{CO}_{2}$ up to this moment (known as split time, see Fig. 17) is considered to be OC. All remaining CA evolved after the split time is instead accounted as EC.

Similarly to optical methods for determining BC, thermal methods do not detect EC and OC directly, and their quantification depends on the setting of the operative conditions during the analysis. It is then noteworthy that TOT/TOR methods do not physically separate the two CA fractions, but simply correct the measured concentration values exploiting EC optical proprieties. This is, in fact, the second main and crude assumption of the methodology: EC is the only light absorbing compound present in $\mathrm{PM}$, while OC is completely transparent to visible light. The analytical result is therefore an operational definition, related to a given protocol, and possibly dependent on PM composition. A protocol consists of a sequence of thermal steps of different 


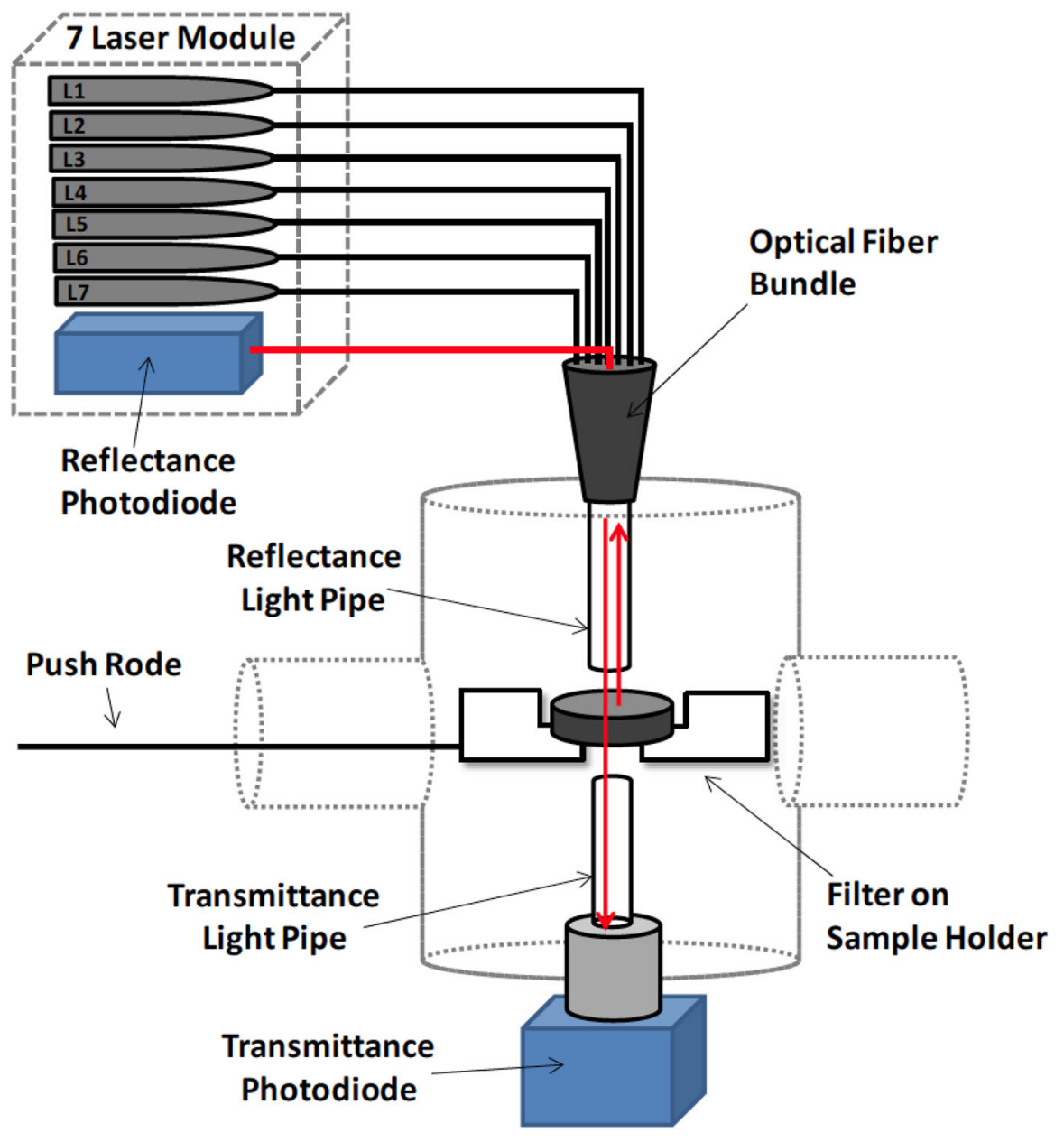

Fig. 18 Configuration of optical sensing modified from the DRI Model 2001 analyzer [162]. The sevenlaser module represents seven diode lasers with wavelengths of 405, 450, 532, 635, 780, 808, and $980 \mathrm{~nm}$. Extracted from [163]

intensity and temporal width during both the heating ramps. Since the choice of the protocol affects EC/OC separation, several specific procedures has been developed in the last decades, with differences in number, temperature and duration of the thermal steps of both heating ramps (inert and oxidizing), aiming to limit the charring artifacts and/or improve the optical corrections [48,164-166]. Many papers in the literature show discrepancies among results obtained with different protocols, mainly for EC values often varying by a factor two or even more [167-169]. Significant differences can also arise when the correction for charring is performed using optical reflectance or transmittance $[164,166,170]$. An interesting and relatively simple methodology to reduce the quoted uncertainties consists in "washing" the PM samples before the analysis with different solvents, thus minimizing PyrC formation. This procedure can 
remove, as an example, water soluble organics prone to charring as well as PM compounds that can act as catalysts, thus resulting in more straightforward and stable results [171-173].

One discussion apart should be dedicated to uncertainties linked to calibration issues. In fact, a reference standard for EC is still missing, and the only possibility to check the functionality of the instruments is limited to calibration runs with a known quantity of OC (typically sucrose) only. This problem often produces systematic discrepancies among different instruments/laboratories performing the analysis on the same sample [174].

Further difficulties arise when the sample in analysis includes colored/refractory organic compounds and/or some kind of light absorbing dust, since one of the basic assumptions in TOT/TOR methods is that EC is the only light absorbing species present in PM. In such situation (not infrequent), the laser signal can be biased/influenced by the "non-EC" absorbing particles, leading again to an erroneous EC/OC separation $[163,175]$. In this case, information about the fraction of light absorbed by the non-EC compounds can be used to correct the laser bias and derive a new split time depending by EC only [176].

In recent studies, the red wavelength typically used in TOT/TOR measurements $(\lambda \approx 660 \mathrm{~nm}$ ) has been integrated with a set of several diodes with wavelength ranging from IR to near UV. This improvement allowed thermal spectral analysis (TSA) and wavelength dependent OC and EC quantification [163,175]. One of the objectives of this recently born line of research is to better understand how different carbon species (and not only) are transformed by thermal energy; this information would help to better quantify not only EC and OC, but hopefully also their sub-fractions, starting with $\mathrm{BrC}$ [158]. The coupled use of non-destructive optical analysis (MWAA) followed by a thermo-optical cycle, has been exploited for the first time in [176] to obtain an operative quantification of the $\mathrm{BrC}$ content in $\mathrm{PM}$ samples collected wintertime in a rural site impacted by biomass burning. Multi-wavelength measurements have shown different EC and OC quantification depending not only on protocol but also on the wavelength used for charring correction, as can be seen in Fig. 19 [158,177].

Finally, thermal-optical analyses are time and man-power consuming and the portion of the sample under analysis gets destroyed however they are the sole rapid approach (i.e. avoiding a long sequence of organic chemistry ) able to provide the OC concentration as a whole, even if without any information on primary versus secondary compounds.

\subsection{Photo-acoustic methodologies}

Photoacoustic spectroscopy (PAS) represents a widespread option for the detection of greenhouse gases such as $\mathrm{CO}_{2}$ and $\mathrm{NO}_{2}$ [178] as well as for the measurement of aerosol particles [179-181]. In the panorama of techniques for the BC quantification via radiation absorption, PAS conjugate fast response rate and large dynamic range, spanning typical over four orders of magnitude. Commercial instruments for measuring BC concentrations reach detection limits of few $\mathrm{ug} \mathrm{m}^{-3}$ (corresponding to 10 $\mathrm{Mm}^{-1}$ for $1 \mathrm{~s}$ integration time) and often integrate a nephelometer [178] to measure 


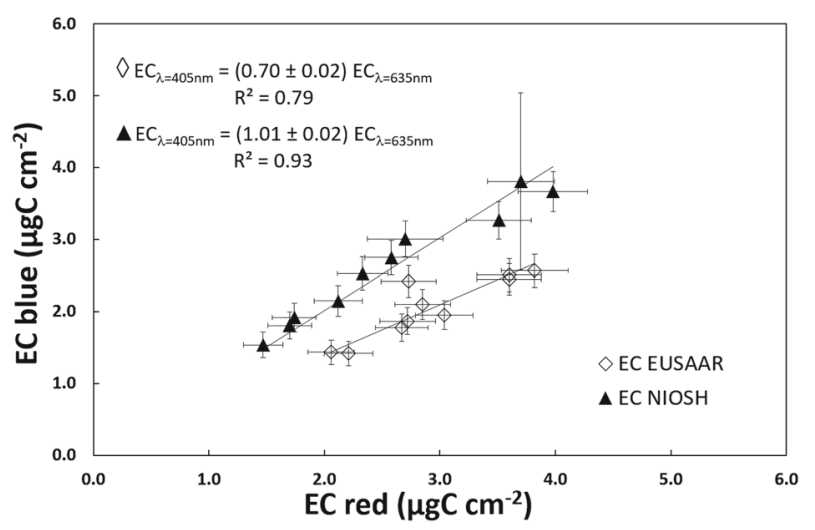

Fig. 19 EC concentration measured in two subsets of PM10 samples collected in consecutive days in a typical urban area. Values were determined by TOT using NIOSH5040 [47] and EUSAAR_2 [48] protocols, both performed with a TOT instrument equipped with blue and red laser diodes. Extracted from [158]

A

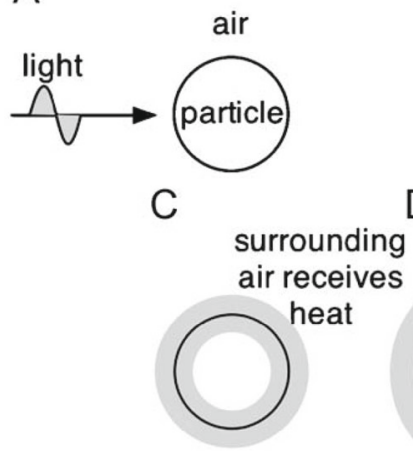

B

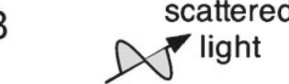

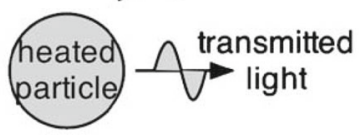

D sound wave

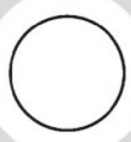

Fig. 20 The basic principle of PAS: a monochromatic light beam hits a single aerosol particle (a) and is eventually scattered or absorbed (b). The adsorbed energy heats the particle and then the surrounding air (c) with a local variation of the density and hence the generation of an acoustic wave (d). The phenomenon is the same occurring in the free atmosphere where possibly produces a positive climate forcing. Extracted from [45]

the scattering coefficient too. After the interaction between laser light and particles, absorbed energy is released in the form of acoustic waves expanding in every direction (Fig. 20).

Acoustic waves are detected by sensitive microphones, and the intensity of the signal is interpreted to infer the absorption coefficient. If the particles are smaller than few hundred nm, the amplitude of the acoustic wave produced is proportional to the absorbed light energy and to the CA mass absorption [183]. Main advantages of PAS are the online measurement of $\mathrm{BC}$, and provided two or more units working at different wavelength are available, real time source apportionment can be performed [184]. 
Known problems of the technique regard ambient gas phase absorbers as well as high relative humidity conditions that can interfere with BC detection $[185,186]$.

\subsection{Laser-induced incandescence methodologies}

In recent years a new technology for the measurement of carbon in atmospheric aerosol has become emergent, knowing a quite fast diffusion: the Single Particle Soot Photometer (SP2). This instrument exploits a peculiar signal to measure refractory carbon (rBC), i.e. laser-induced incandescence, detectable as visible thermal radiation [187189]. The methodology consists in heating to vaporization temperatures (around 4000 $\mathrm{K}$ ) single $\mathrm{rBC}$ particles by means of an infrared intra-cavity laser, so that thermal radiation proportional to $\mathrm{rBC}$ mass is detected. The SP2 detects $\mathrm{rBC}$ core volume-equivalent size, considering a void-free material density of $1800 \mathrm{~kg} \mathrm{~m}^{3}$, in the dimensional range $80 \mathrm{~nm} \div 600 \mathrm{~nm}$. For soot BC, the integrated mass obtained by SP 2 has been validated as accurate by several independent studies in recent years [190-192]. Main advantages of SP2 are the possibility to have online measurements of BC containing particles, over a quite large range of mass concentrations, with information on size too. Hints on coating materials and/or on internal mixing of BC particles can be achieved, especially in the case of volatile materials [193-195]. Smaller rBC particles can also be detected, although with reduced counting efficiency [192]. The main source of uncertainty when measuring real aerosol is due to calibration issues, since the technique sensitivity is ambient-rBC dependent; the sensitivity range has been reported to be within $15 \%$ [196,197]. Moreover, difficulties related to the measurement of smaller particles can influence results depending on size distribution of the aerosols. While in remote sites SP2 can measure most of the mass and about only half of the rBC particles, in urban environment the loss can reach easily $20-25 \%$ in mass $[198,199]$.

\subsection{Other laser-based methodologies}

Another useful instrument to obtain information on carbonaceous particles by exploiting their optical properties is the Cavity Attenuated Phase-Shift Single Scattering Albedo Monitor (CAPS PMssa), recently introduced by Aerodyne Res. Inc. [200]. This instrument represents the evolution of the Cavity Attenuated Phase-Shift Particle Extinction Monitor (CAPS PMex) [201,202], since to measure light extinction it uses the same methodology and structure, but includes a small integrating sphere to measure also light scattered by particles at all angles (except the line of laser propagation, i.e. $\approx 0^{\circ}$ and $\approx 180^{\circ}$ ). While the system measures light extinction by determining the change in signal phase shift caused by the particles introduced in an optical resonator, the integrating sphere acts as a nephelometer, thus providing the aerosol scattering coefficient. It follows that the absorption coefficient has to be derived as the difference between extinction and scattering coefficients. Although the CAPS PMssa cannot directly measure aerosol light absorption, it has been proved to be a reliable instrument for the measurement of the absorption coefficient too, with best performances occurring for small particle sizes showing intermediate SSA values [203]. Worst per- 
formances of the instrument are likely present in case of weakly absorbing particles as large-sized and irregularly shaped mineral dust particles.

In the last few years a new technique has been introduced: the Single Particle Extinction and Scattering (SPES) [204]. SPES, originally developed to operate with liquid suspensions of particles [205], has proven to be reliable to simultaneously measure the real and imaginary parts of the forward scattered field of a population of aerosol particles in air, providing particle size and refractive index under few or no assumptions [206]. This technique appears to be quite promising, especially for studying properties of absorbing particles like BC, since in principle it can provide particle size and imaginary part of the refractive index, under assumptions on its real part. This is possible thanks to single-particle measurements of untreated samples, allowing to either recover detailed statistical properties of the analyzed population or average properties obtained by integrated measurements.

\subsection{Radiocarbon: beyond the dating}

Radiocarbon analysis of CA deserves a dedicated discussion since it is often used as reference method for OC/EC source apportionment starting from optical analyses (see Sect. 4.8); furthermore the latest developments of the technique exploit thermo-optical analyses.

The possibility to adopt the ${ }^{14} \mathrm{C}$ determination beyond the well know dating methodology was suggested quite soon after Libby's initial works [207]. The first attempt to apply natural ${ }^{14} \mathrm{C}$ to the apportionment of fossil and biomass combustion aerosol took place in Pasadena, California in the year 1955 [208]. Due to the technical limitation of the time (in particular the ${ }^{14} \mathrm{C}$ determination was conducted via $\beta$ counting by a liquid scintillator) it was necessary to prolong the PM sampling for nearly a week to collect about $42 \mathrm{~g}$ of PM and finally $8.5 \mathrm{~g}$ of carbon. From that first experiment, several progresses have been made continuously improving the sensitivity of the technique: a jump forward was the transition from $\beta$ counting to the direct determination of the ${ }^{14} \mathrm{C}$ to $\left({ }^{12} \mathrm{C}+{ }^{13} \mathrm{C}\right)$ concentration ratio by Accelerator Mass Spectrometry [209] (AMS) ([210] and references therein) which resulted in the reduction of the minimum quantity of carbon to guarantee a detectable signal in the range of $10 \mu \mathrm{g}$.

Actually, the ${ }^{14} \mathrm{C}$ method provides a direct separation of contemporary and fossil carbon in ambient aerosols, because ${ }^{14} \mathrm{C}$ has decayed in fossil material. The ${ }^{14} \mathrm{C}$ to ${ }^{12} \mathrm{C}$ concentration ratio is usually referred as fraction of modern carbon (fM). Values for fM should range from 0 for fossil fuel (FF) sources to 1 for particles from the modern biosphere. However, in samples of the last sixty years, fM turns out to be $>$ 1 , with maximum values of $\mathrm{fM}=2$ in the early 1960s, as a consequence of the nuclear bombs testing in the atmosphere [211]. Considering the mixing in the atmosphere of ${ }^{14} \mathrm{C}$ abundances in the last decades, a reliable estimate of the present value for PM produced by biomass burning $(\mathrm{BB})$ is $\mathrm{fM}=1.24 \pm 0.05$ [212]. The determination of the $\mathrm{fM}$ value in the carbonaceous aerosol makes thus possible an apportionment of anthropogenic and biogenic sources but biomass burning emissions, which in a large fraction should be considered of anthropogenic origin, can remain not separated from biogenic emissions, as both sources contribute to the contemporary fraction of car- 


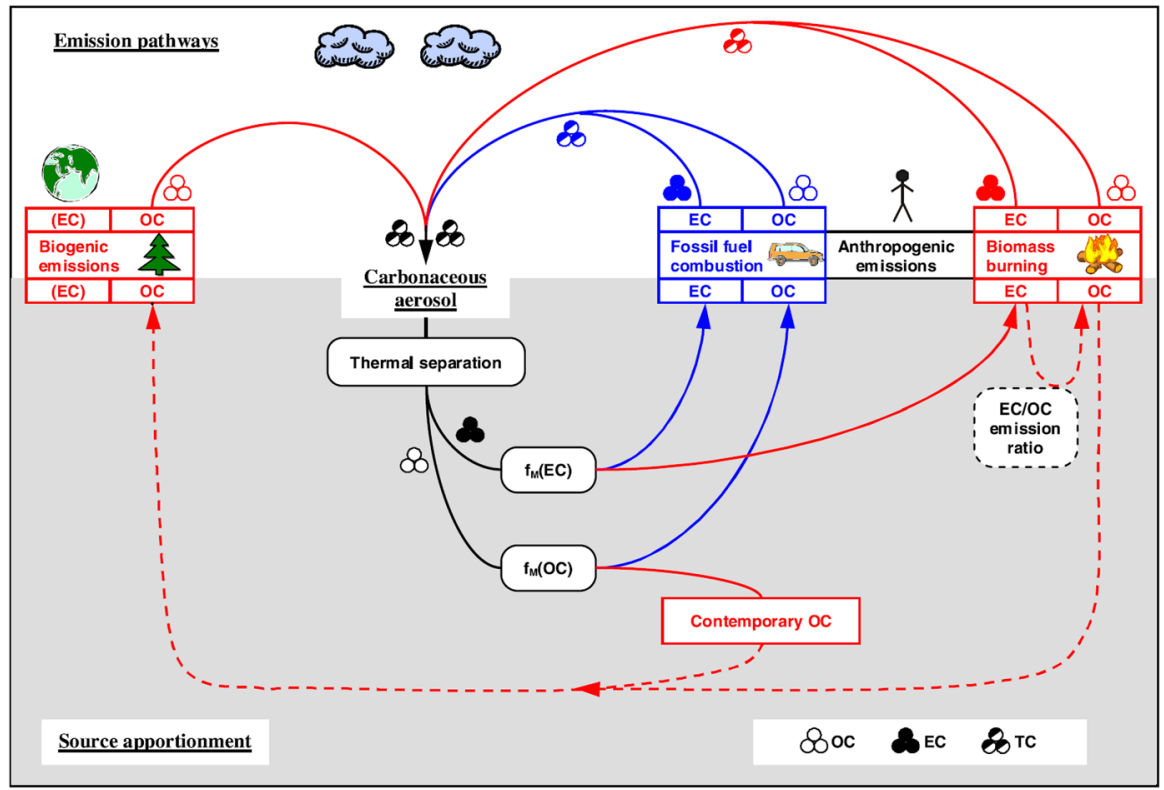

Fig. 21 Main emission pathways of OC, EC, and TC and their apportionment according to the advanced ${ }^{14} \mathrm{C}$ model introduced in [214]. Source patterns of the different fractions are distinguished between fossil carbon (blue), contemporary carbon (red), and mixtures of both (black). Dashed lines indicate supplements of the source apportionment model to often employed simple two-source ${ }^{14} \mathrm{C}$ models. Biomass burning was assumed as an anthropogenic source, thus neglecting naturally occurring wood fires as a biogenic EC source. Extracted from [214]

bonaceous aerosols ([213] and references therein). This limitation has been overcome by the more recent apportionment approach [214]: first EC and OC are extracted by PM samples and, after combustion, evolving $\mathrm{CO}_{2}$ is separately trapped and transformed to filamentous carbon for ${ }^{14} \mathrm{C} /{ }^{12} \mathrm{C}$ analysis by $\mathrm{AMS}$, for instance at the PSI/ETH compact accelerator system [215]. By the AMS analysis, the fM value is determined separately for the EC and OC extracted from each sample and through an articulated but relatively simple data reduction procedure [214], the apportionment in terms of $\mathrm{EC}_{F F}, \mathrm{EC}_{B B}, \mathrm{OC}_{F F}, \mathrm{OC}_{B B}$ and $\mathrm{OC}_{B I O}$ is obtained (with $\mathrm{OC}_{B I O}$, corresponding to the fraction of contemporary OC produced by biogenic emissions, is calculated as the difference $\left.\mathrm{OC}-\mathrm{OC}_{F F}-\mathrm{OC}_{B B}=\mathrm{OC}-\mathrm{OC}_{a n t h}\right)$. A schematic view of the relationship between each term and the PM sources is given in Fig. 21.

The procedure was also validated by comparison of the $\mathrm{OC}_{B B}$ values with $\mathrm{OC}_{B \text { Blevo }}$, the latter being an independent determination of the $\mathrm{OC}$ fraction produced by biomass burning based on the levoglucosan quantification. Levoglucosan is an organic molecule and a well known tracer of biomass burning: it can be detected in PM samples by chemical methodologies [216]. The first application of the updated ${ }^{14} \mathrm{C}$ apportionment was on PM samples collected in the urban area of the city of Zurich $(\mathrm{CH})$ and yielded a significant contribute of $\mathrm{BB}$ to both $\mathrm{OC}$ and $\mathrm{EC}(\mathrm{EC} \approx 6 \%, 12 \%, 25 \%$, respectively in summer, spring and winter; OC-winter $\approx 41 \%, 32 \%, 27 \%$ and OC- 


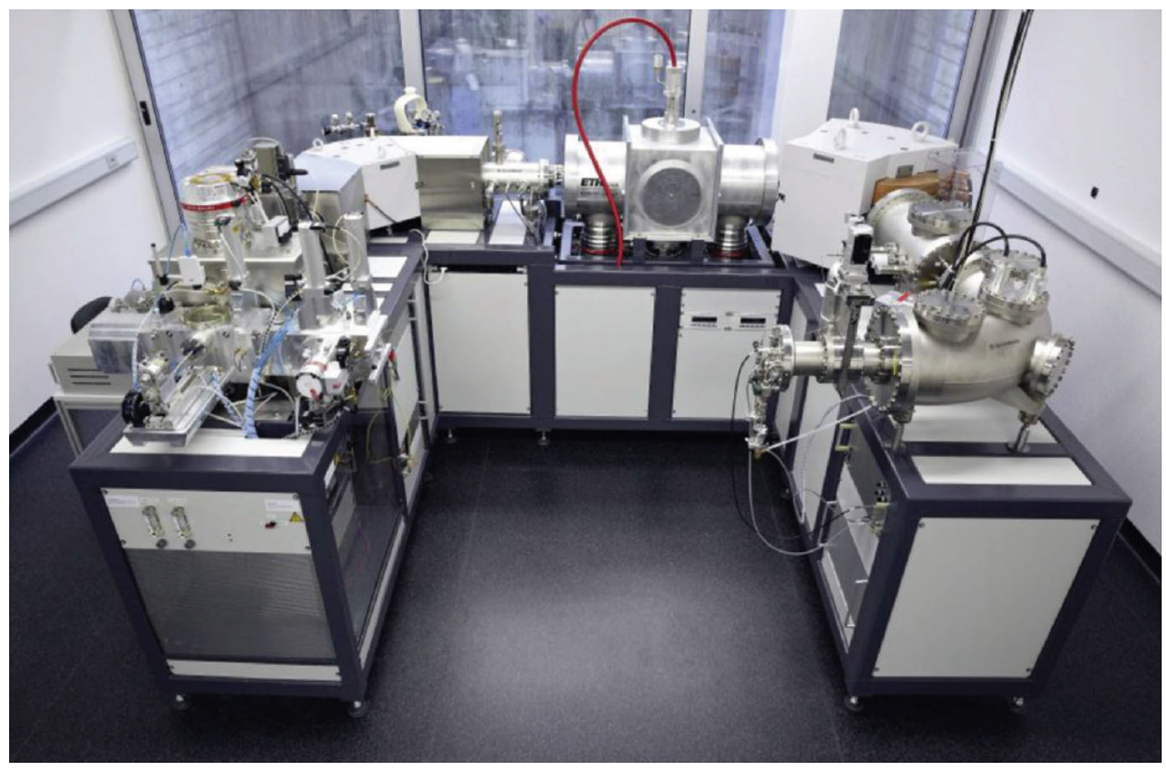

Fig. 22 The MICADAS (MIni CArbon DAting System) at LARA-Bern. Extracted from [220]

summer $\approx 10 \%, 31 \%, 60 \%$ summer, respectively for BB, FF and biogenic emissions [214]).

To be analysed by AMS, radiocarbon samples have to be properly prepared to be inserted into the ion source of the accelerator (for instance as graphite pellets for a sputtering ion source [217]). The preparation procedure must fulfil specific requirements for aerosol samples: separation of OC and EC, handling of low sample mass, quality assurance to avoid contamination from laboratory environment. There are no many laboratories worldwide fulfilling such stringent requirements. At INFN-LABEC (Istituto Nazionale di Fisica Nucleare - Laboratorio per Analisi di BEni Culturali ed ambientali), Florence (IT), an AMS set-up for the preparation of aerosol samples with a minimum Carbon mass of $100 \mu \mathrm{g}$ has been developed [218]. At LARA (Laboratory for the Analysis of Radiocarbon with AMS) at the University of Bern $(\mathrm{CH})$, a compact AMS system (MICADAS: MIni Carbon DAting System, see Fig. 22) which allows to accelerate directly the $\mathrm{CO}_{2}$ released during the thermo-optical analysis of aerosol samples [219] has been designed for routine analysis of large amount of samples [220]. Actually, during the first 8 months after the deployment, more than 400 gas samples with carbon masses down to $3 \mu \mathrm{g}$ have been analyzed by the MICADAS equipment [220].

\subsection{Bioaerosol monitors}

The detection of biological aerosol particles (i.e. viruses, bacteria, fungi, spores, pollens, biological debris) falls largely outside the limits of the techniques usually adopted in physics and chemistry research. The majority of bioaerosol analyses historically 
utilized microscopy or cultivation-based techniques [221]. Both the approaches cannot be utilized for real-time analysis as well as for the off-line DNA analysis (Polymerase Chain Reaction, PCR, [222] and references therein). Cultivation techniques miss the diversity and abundance of bioaerosols because the vast majority of microorganism species are not culturable ([223] and references therein).

Spectroscopy methods offer further possibility both for off-line and on-line bioaerosol equipment. Molecules exposed to electromagnetic radiation can either absorb or scatter incoming photons. If energy is adsorbed by a molecule it can be dissipated either radiatively, non-radiatively, or through a combination of both (e.g. fluorescence, phosphorescence). Molecular fluorescence can be seen as an inelastic light scattering process (i.e. energy is imparted to the molecule) causing the excitation electrons to vibrational states and subsequent de-excitation with possible radiative emission (fluorescence) or through a variety of non-radiative processes (quenching), depending largely on the local molecular environment [224]. Emission wavelengths are characteristic for a given fluorophore. This is the basic of optical detection of bioaerosol which led to the development of rapid techniques for the real-time characterization and quantification of airborne biological particles ([225] and references therein).

A diffused technique is based on ultraviolet laser/light-induced fluorescence (UVLIF) [226]. The two most commonly applied UV-LIF bioaerosol sensors are the wideband integrated bioaerosol sensor (WIBS, Droplet Measurement Technologies, Longmont, CO, USA) and the ultraviolet aerodynamic particle sizer (UV-APS; TSI, Shoreview, MN, USA). Both the equipment implement a pulsed ultraviolet light beam to excite fluorescence in aerosol particles continuously flowing through a proper cell. The excitation and emission wavelengths are chosen to detect biological fluorophores usually present in airborne microorganisms (e.g., tryptophan-containing proteins, NAD(P)H co-enzymes, or riboflavin) [224]. The WIBS has become probably the most diffused instrument: aerosol particles first pass through a laser beam $(\lambda=635 \mathrm{~nm})$ for optical determination of their size (in the range $0.5-30 \mu \mathrm{m})$ and asphericity and downstream are excited by two UV flashlamps $\left(\lambda_{1}=280 \mathrm{~nm}\right.$ and $\lambda_{2}$ $=370 \mathrm{~nm}$ ). Fluorescence emission is detected in two separate bands: band $_{1}$ at 310 $<\lambda<400 \mathrm{~nm}$ and band $_{2}$ at $420<\lambda<650 \mathrm{~nm}$. For each single particle entering the instrument, a set of information is thus collected in list mode, giving the possibility to perform a multi-parametric off-line analysis to classify/resolve different types of bio and not-bio aerosol species [227,228]. An example is given in Fig. 23.

The WIBS analysis has been already adopted in several research works listed in [228], where the result of a systematic classification of many aerosol particles (bio and not bio) is also reported.

\subsection{Progresses in the apportionment of carbonaceous aerosol}

We have underlined the role of CA in source apportionment evaluations (Sect. 3.3). The measurement of the concentration of specific compounds and/or categories in PM samples is carried out through the techniques discussed in the previous sections. In the case of $\mathrm{OC}$ and $\mathrm{EC}$, the ${ }^{14} \mathrm{C}$ analysis can directly provide the apportionment between fossil fuel and biomass burning and, by difference, the fraction of biogenic 

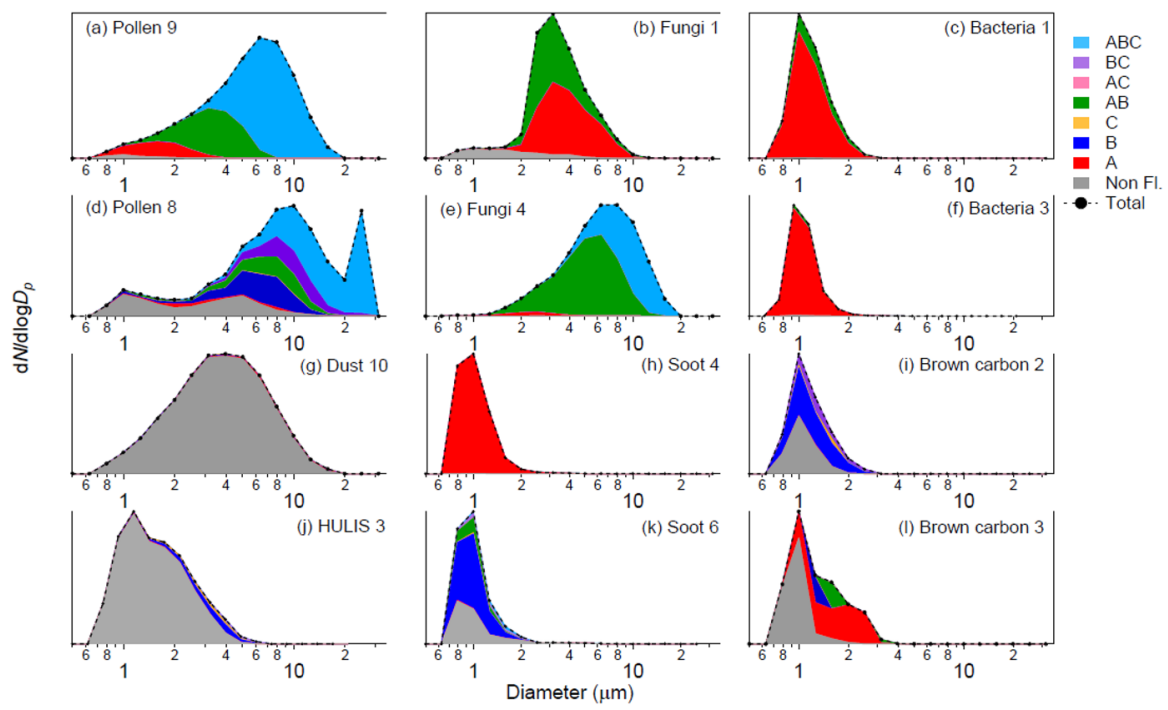

Fig. 23 Stacked particle type size distributions including particle type classification. Examples of each material type were selected to show general trends from larger pool of samples. The size distribution measured by optical scattering at $\lambda=635 \mathrm{~nm}$ is further disentangled considering for each particle the presence of a signal of type A,B,C, and/or their combination. A,B,C, refer to (see text): $\mathrm{A}=\mathrm{UV}$ excitation at $\lambda_{1}$ and emission in band ${ }_{1} ; \mathrm{B}:=\mathrm{UV}$ excitation at $\lambda_{1}$ and emission in band ${ }_{2}, \mathrm{C}:=\mathrm{UV}$ excitation at $\lambda_{2}$ and emission in band 2 . The label Non FL stands for Not Fluorescence. Soot $4(\mathrm{~h})$ is an example of combustion soot and Soot 6 (wood smoke) is an example of smoke aerosol. Extracted from [228]

OC. Figure 12 reports one of a first attempts to join composition and optical information for a better identification of PM sources in an urban area. In such complex and evolving frame, the apportionment methodologies based on optical techniques play a peculiar role since they can both evaluate the contribute of specific CA sources to the PM absorption, and hence to its forcing, but also provide a simple and fast way to retrieve the concentration fraction of $\mathrm{BC}$ and $\mathrm{BrC}$ due to specific sources.

The relationship between the wavelength and the aerosol absorption coefficient, $\mathrm{b}_{a b s}$ is generally described by the power-law $\mathrm{b}_{a b s} \propto \lambda^{-A A E}$ where AAE is the Angstrom Absorption Exponent [45], which value depends on PM composition and particle size and morphology [45,229-231]. At two different wavelengths the simple relation holds:

$$
\frac{b_{a b s}\left(\lambda_{1}\right)}{b_{a b s}\left(\lambda_{2}\right)}=\left(\frac{\lambda_{1}}{\lambda_{2}}\right)^{-\alpha}
$$

where $\alpha$ is a generic value of the AAE; values $\alpha \approx 1$ have been reported for $\mathrm{BC}$ and $\alpha$ up to 9.5 for $\mathrm{BrC}$ [232]. Multi-wavelength optical techniques have been proposed to separate biomass burning and traffic contributions adopting the so-called Aethalometer model $[233,234]$. The model takes the name from the on-line instrument and identifies the two main EC and OC sources (i.e. fossil and biomass burning) avoiding laboratory analyses on PM samples. In the approximation of the Aethalometer model, fossil fuel (FF) and wood burning (WB) are considered to be the only sources of light absorbing 
species in the PM and hence:

$$
b_{a b s}(\lambda)=b_{a b s F F}(\lambda)+b_{a b s W B}(\lambda)
$$

where $\mathrm{b}_{a b s F F}$ and $\mathrm{b}_{a b s W B}$ are the FF and WB fractions to the total $\mathrm{b}_{a b s}$ and boths are assumed to follow the general relationship $\mathrm{b}_{a b s} \propto \lambda^{-\alpha}$, where the exponent $\alpha$ has different values for FF and WB ( $\alpha_{F F}$ and $\alpha_{W B}$, respectively). In the original formulation of the Aethalometer model [233,234], the two exponents are set to $\alpha_{F F}=1$ and $\alpha_{W B}$ $=2$, through a comparison with literature data and radiocarbon analyses. While the choice of the $\alpha_{F F}$ value relies on a large set of observations, the $\alpha_{W B}$ exponent can be much more site dependent since the characteristics of the combustion processes, the type of biomass fuel, the ageing of the carbonaceous aerosol are highly variable, and determine the $\mathrm{BC}: \mathrm{BrC}$ ratio and finally the $\mathrm{CA}$ optical properties (including the absorption). Once fixed the $\alpha_{F F}$ and $\alpha_{W B}$ values, the FF and WB fractions to EC and OC are obtained fitting from two to seven $b_{a b s}(\lambda)$ values for each sample or period of the Aethalometer time series (technical details on the fitting and decomposition procedure in $[233,234])$. As in the Aethalometer case, the multi-wavelength measurement of the light extinction coupled with a thermo-optical determination of EC and OC (see Sect. 4.2), is the basis of a similar methodology described in[235].

A step forward in the direction tracked by Aethalometer model has been made with the MWAA described in Sect. 4.1. Actually, the development of the MWAA set-up also introduced an improvement of the apportionment procedure named as "MWAA model" [146,236]. In this case, BC and BrC are considered to be the only light-absorbing species in the aerosol sample. Hence, disregarding the link with the emission sources, the relation holds:

$$
b_{a b s}(\lambda)=b_{a b s B C}(\lambda)+b_{a b s B r C}(\lambda)
$$

As for the Aethalometer model, the wavelength dependence of each component of the absorption coefficient is assumed to be $\propto \lambda^{-\alpha}$. The value of the exponent $\alpha_{B C}$ is taken equal to $1[45,237]$ even if other choices could be implemented in the model keeping valid the mathematical approach. Fitting the multi-wavelength raw data provided by the MWAA or similar instruments $[146,154]$, the $b_{a b s B C}$ and $b_{a b s B r C}$ values can be determined for each sample; furthermore the model directly provides the value of the $\alpha_{B r C}$ exponent, a piece of information still very scarce in the literature [236,238]. Finally, putting together eq. 10 and 11 and under the conditions: (i) $\alpha_{F F}=\alpha_{B C}$; (ii) $\mathrm{BrC}$ is emitted by wood burning only, the values of $\mathrm{b}_{a b s B C}^{F F}, \mathrm{~b}_{a b s B C}^{W B}$ and $\mathrm{b}_{a b s B r C}$ are retrieved for each sample as in the example shown in Fig. 24.

As with the Aethalometer model, the "optical apportionment" (e.g. Fig. 24), is the basis for deducing the $\mathrm{EC}$ and $\mathrm{OC}$ apportionment i.e. the values of $E C_{F F}, E C_{W B}$, $O C_{F F}, O C_{W B}, O C_{N C}$, where the latter indicates the fraction of OC not originated from combustion processes (details on the data reduction procedure in $[146,236]$ ). Despite some limitations and approximations (e.g. difficulties in apportioning aged secondary aerosols, lack of sensitivity to other aerosol species with high absorbance as dust) the MWAA model has been successfully tested against independent techniques (i.e. radiocarbon and chemical determination of levoglucosan as BrC marker [146, 


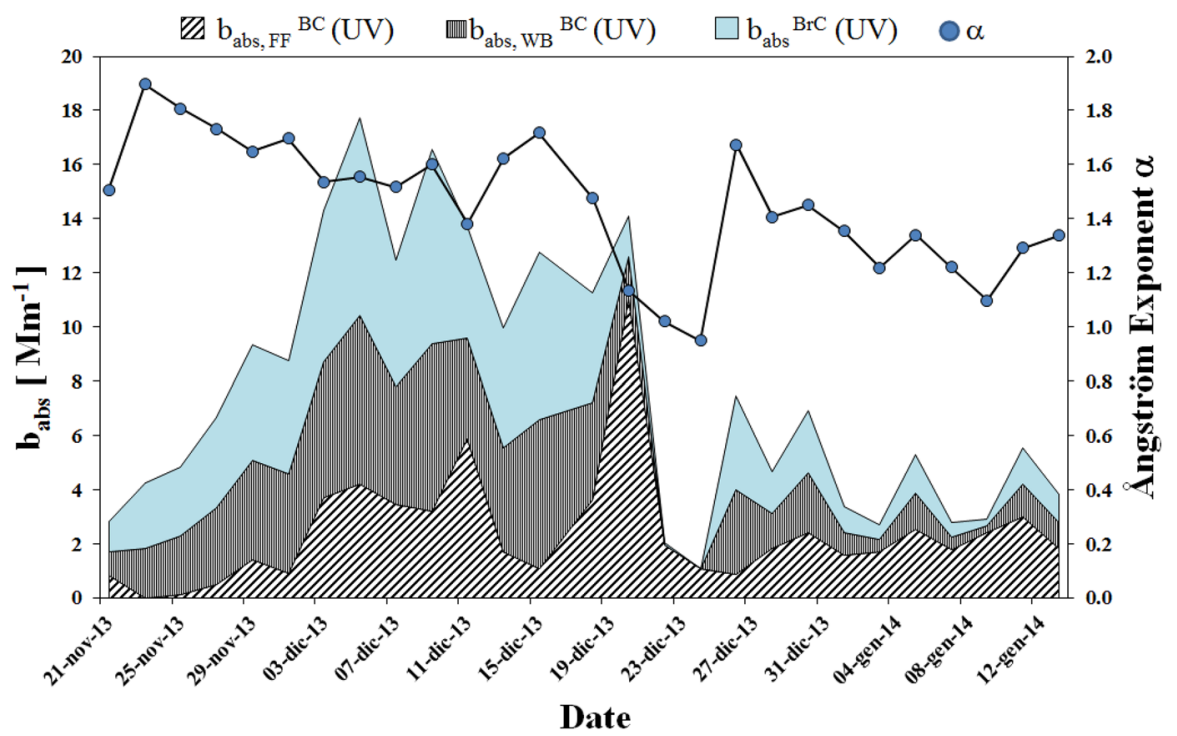

Fig. 24 Apportionment of the absorption coefficient $b_{a b s}$ obtained wintertime at a rural site in the Italian Apennines at $\lambda=375 \mathrm{~nm}$ (UV). The raw value of the absorption Angstrom is also shown on the right axis. Extracted from [146]

236]). The model can provide the $\lambda$ dependence of $\mathrm{BrC}$ absorption at different sites, as well as the information on MAC of EBC and $\mathrm{BrC}$, when the knowledge of $\mathrm{EC}$ mass is available by other analytical techniques (in primis the thermo-optical analysis described in Sect. 4.2).

\section{Conclusions}

The future challenges in the characterization of carbonaceous aerosol have been partially anticipated in the previous sections. Here we underline the main open issues to which the research effort will likely focus in the next years.

$\mathrm{EC}$ or $\mathrm{BC}$ are often proposed as new items in an upgraded list of atmospheric pollutants to be regulated and hence monitored. As a consequence, a concentration limit for $\mathrm{EC}$ or $\mathrm{BC}$ should also be introduced in the air quality legislation. Such possibility is pushed by the consideration that the present limits on PM10 and PM2.5 concentration values appear to be not adequate to protect the human health (see Sect. 3.1). A similar argument has been proposed for nanoparticles (i.e. aerosol particles with aerodynamic diameter $\leq 100 \mathrm{~nm}$ ) too [239]. A conclusive evidence is still missing both for $\mathrm{EC} / \mathrm{BC}$ and nanoparticles. There are several reasons for such unpleasant situation starting from the ambiguity in the use of the partially overlapping definitions of $\mathrm{BC}$, EC, EBC (see Sect. 2) together with the persisting use of older terms as "soot". The term EBC has been so far introduced [51] to reduce the ambiguity and to uniform the huge amount of data continuously produced worldwide but it has not yet adopted as mandatory standard in any regulatory act. In the present situation there is a lack of 
scientific support for the extrapolation of epidemiological and toxicological findings since $\mathrm{BC} / \mathrm{EC}$ data actually refer to various/different types of particles and therefore of risk associated to the human exposure [240]. In other terms BC (exactly as OC, EC and $\mathrm{BrC}$ ) is just an "operative" definition which does not correspond to a well defined atomic/molecular composition/structure. Furthermore, a standard reference material is presently not available. The situation is largely worst for $\mathrm{BrC}$, still far to be considered outside the precinct of basic research. Efforts to improve the traceability of BC measurements are on the way in the frame of large international initiatives/projects, as the ACTRIS (Aerosol Clouds and Trace gases Research InfraStructure, https://www. actris.eu/), which is going to build in Europe the largest world distributed infrastructure for the study of atmospheric processes.

The most diffused approaches to the monitoring of carbonaceous aerosols (i.e. optical and thermo-optical equipment) every day provide worldwide a huge quantity of information but are at the same time biased by several artifacts. The problems in measuring the light absorption and in resolving the OC/EC fraction during the thermal evolution of aerosol samples have been discussed in detail in this review article (see Sects. 4.1 and 4.2). The possibility to get in the future a firm, shared and fully assessed thermo-optical determination of the OC and EC fraction seems unlikely. The issue related to the charring is intrinsically dependent on the PM composition and ageing even neglecting the relationship between the split point position and the wavelength of the light source adopted in a specific instrument. On the other side, the operative quantities $\mathrm{OC}, \mathrm{EC}$ (and $\mathrm{BrC}$ and $\mathrm{BC}$ too) make possible a quick and diffused collection of the environmental data necessary to evaluate the climatic impact of CA. In this frame, a step forward could come form the coupling of the well controllable thermal quantification of TC with a reliable optical determination of BC. This way, even not resolving the partial mismatching between $\mathrm{BC}$ and $\mathrm{EC}$, the $\mathrm{OC}$ concentration could be simply determined as $\mathrm{OC}=\mathrm{TC}-\mathrm{BC}$. Furthermore, a multi-wavelength optical analysis can separate $\mathrm{BC}$ and $\mathrm{BrC}$ and their sources. This is the way followed by new instruments, very recently introduced in the market and therefore still not completely discussed in the literature. The Magee Scientific Carbonaceous Aerosol Speciation System (CASS; https://mageesci.com/cass/), is a combined unit of a Total Carbon Analyzer (model TCA08) and of an Aethalometer (model AE33), providing a quasireal time determination of TC and BC, and hence of OC. The Magee approach has a high potential, provided the limits of the Aethalometer (see Sect. 4.1) are fully resolved. The implementation in the instrument software (or off-line, in a refined data reduction) of a more advanced apportionment model (see Sect. 4.8) could further improve the applicability of such new and powerful equipment. A similar direction, at the moment limited to just one wavelength, has been taken by Dadolab (https:// www.dadolab.com/) which developed a new PM sampler called GIANO BC1. In this case, a sequential PM sampler, fully compliant with the US-EPA and EU standards for PM10 and PM2.5 sampling, has been modified to allow a quasi real-time BC determination during the sampling phase. With GIANO BC1 the $\mathrm{BC}$ concentration is measured by a reflectance-driven monitoring of the sample absorbance, implementing a simplified MAAP approach. At the conclusion of the sampling, the PM concentration can be retrieved by a standard gravimetric analysis and the filter can be also used for speciation purposes, in particular for a thermal and/or thermo-optical analysis to 
retrieve TC, EC and OC. This way, the optical BC determination appears to be more robust with respect to the attenuation-based instruments but an upgrade to a multiwavelength set-up would be desirable. Finally, the evolution of the optical equipment for $\mathrm{BC}$ and $\mathrm{BrC}$ determination should take into account other absorbing species in the $\mathrm{PM}$ as the $\mathrm{Fe}_{2} \mathrm{O}_{3}$-rich dust transported from the desert areas of the planet for thousands of $\mathrm{km}$. In this perspective, the transition from the current multi-lambda instruments to a new generation of devices operating with continuum light source would be necessary, provided enough sensitivity can be assured. In a long term view and looking for a final assessment, the number of instruments for CA characterization has to be drastically reduced to hopefully arrive to a single (or to a few) reference and well controllable (i.e. with fully referenced quality assurance protocol) techniques. The goal requires a coordinate action and the development of large research infrastructures (as ACTRIS) will be decisive since the present fragmentation of the research effort is one of the limiting factors to a homogeneous quality of the data. The impact of CA (actually, of all the airborne aerosol particles) on the global climate is just the most outstanding reason to push toward a more coordinated research activity.

In the next future the research on CA will likely systematically address the environmental impact of bioaerosol, fungi and bacteria in particular, and new instruments (see Sect. 4.7) are going to improve our knowledge. The in-field experiments on bioaerosol behaviour are hampered by the not-controllable complexity of the atmospheric medium. A new generation of multi-disciplinary research facilities, where the microbiology methodologies could be coupled with realistic atmospheric environments (as those inside the Atmospheric Simulation Chambers [73,74]), needs to be developed. We did a first small step in this direction with the construction, still in progress, of the Chamber for Aerosol Modelling and Bio-aerosol Research (ChAMBRe), a facility where experiments on the correlation between bacteria viability, meteorological conditions and air quality can be performed with a sensitivity of $10 \%$ [241,242]. Studies on the toxicological load of carbonaceous aerosol, for instance $\mathrm{BC}$, can be (and very likely will be) conducted by atmospheric simulation chambers as well.

The science of atmospheric aerosols was born with the seminal work by John Aitken in 1880 [243]: from that time, the understanding of the multi-faced role of carbonaceous compounds has made impressive progresses but still keeps many open problems and fascinating challenges for a new generation of scientists.

Acknowledgements The authors acknowledge Marco Brunoldi, Silvia Giulia Danelli, Franco Parodi and Virginia Vernocchi of INFN and University of Genoa for the continuous and valuable collaboration to the research work on carbonaceous aerosols.

Funding Open access funding provided by Universitá degli Studi di Genova within the CRUI-CARE Agreement.

Open Access This article is licensed under a Creative Commons Attribution 4.0 International License, which permits use, sharing, adaptation, distribution and reproduction in any medium or format, as long as you give appropriate credit to the original author(s) and the source, provide a link to the Creative Commons licence, and indicate if changes were made. The images or other third party material in this article are included in the article's Creative Commons licence, unless indicated otherwise in a credit line to the material. If material is not included in the article's Creative Commons licence and your intended use is not permitted 
by statutory regulation or exceeds the permitted use, you will need to obtain permission directly from the copyright holder. To view a copy of this licence, visit http://creativecommons.org/licenses/by/4.0/.

\section{References}

1. J. Tyndall, Philos. Trans. R. Soc. Lond. 151, 1 (1861)

2. A.A. Lacis, G.A. Schmidt, D. Rind, R.A. Ruedy, Science 330, 356 (2010)

3. The Intergovernmental Panel for Climate Change Climate Change 2014 - Synthesis Report, edited by IPCC (Geneve) 2015

4. T.C. Bond, R.W. Bergstrom, Environ. Sci. Technol. 40(1), 27 (2006)

5. O. Boucher, D. Randall, P. Artaxo, C. Bretherton, G. Feingold, P. Forster, V. M. Kerminen, Y. Kondo, H. Liao, U. Lohmann, P. Rasch, S. K. Satheesh, S. Sherwood, B. Stevens, X. Y. Zhang. Clouds and aerosols, in: Climate Change 2013: The Physical Science Basis. Contribution of Working Group I to the Fifth Assessment Report of the Intergovernmental Panel on Climate Change, edited by Stocker, T. F., Qin, D., Plattner,G.-K., Tignor, M., Allen, S. K., Doschung, J., Nauels, A., Xia, Y., Bex, V., Midgley, P. M.: Cambridge University Press (New York) (2013)

6. S.S. McKenzie, M. Flanner, J.M. Cook, M. Dumont, T.H. Painter, Nat. Clim. Change 8, 964 (2018)

7. J. Sun, P.A. Ariya, Atmos. Environ. 40, 795 (2006)

8. J. H. Seinfeld, S. N. Pandis, Atmospheric Chemistry and Physics. From Air Pollution to Climate Change, edited by John Wiley and Sons (New York) (1998)

9. K. Acker, S. Mertes, D. Moller, W. Wieprecht, R. Auel, D. Kalasz, Atmos. Res. 64, 41 (2002)

10. P.A. Ariya, J. Sun, N.A. Eltouny, E.D. Hudson, C.T. Hayes, G. Kos, Int. Rev. Phys. Chem. 28, 1 (2009)

11. C. Hoose, J. Kristjansson, S. Burrows, Environ. Res. Lett. 5, 9 (2010)

12. V.R. Desprs, J.A. Huffman, S.M. Burrows, C. Hoose, A.S. Safatov, G. Buryak, J. Frhlich-Nowoisky, W. Elbert, M.O. Andreae, U. Pschl, R. Jaenicke, Tellus B64, 15598 (2012)

13. H. Bauer, H. Giebl, R. Hitzenberger, A. Kasper-Giebl, G. Reischl, F. Zibuschka, H. Puxbaum, J. Geophys. Res. 108, 4658 (2003)

14. P.A. Ariya, M. Amyot, Atmos. Environ. 38, 1231 (2004)

15. R.J. Charlson, Environ. Sci. Technol. 3, 913 (1969)

16. C.F. Bohren, D.R. Huffman. Absorption and scattering of light by small particles, edited by John Wiley and Sons (New York) (1983)

17. A.D.A. Hansen, H. Rosen, T. Novakov, Sci. Total Environ. 36, 191 (1984)

18. International Agency for Research on Cancer International Agency for Research on Cancer, edited by IARC (Lyon) (2017)

19. P. Stier, J. Feichter, S. Kinne, S. Kloster, E. Vignati, J. Wilson, L. Ganzeveld, I. Tegen, M. Werner, Y. Balkanski, M. Schulz, O. Boucher, A. Minikin, A. Petzold, Atmos. Chem. Phys. 5, 1125 (2005)

20. M. Qi, L. Jiang, Y. Liu, Q. Xiong, C. Sun, X. Li, W. Zhao, X. Yang, Int. J. Environ. Res. Public Health 15, 1483 (2018)

21. S.K. Sharma, T.K. Mandal, A. Sharma, S.J. Saraswati, Bull. Environ. Contam. Toxicol. 100, 695 (2018)

22. Y. Feng, Y. Chen, H. Guo, G. Zhi, S. Xiong, J. Li, G. Sheng, J. Fu, Atmos. Res. 92, 434 (2009)

23. D. Ji, M. Gao, W. Maenhaut, J. Hee, C. Wu, L. Cheng, W. Gao, Y. Sun, J. Sun, J. Xin, L. Wang, Y. Wang, Environ. Int. 126, 171 (2019)

24. S. Yoon, S. Usenko, R.J. Sheesley, Atmosphere 11, 482 (2020)

25. A.R. Metcalf, J.S. Craven, J.J. Ensberg, J. Brioude, W. Angevine, A. Sorooshian, H.T. Duong, H.H. Jonsson, R. C. Flagan, J.H. Seinfeld, J. Geophys. Res. 117, D00V13 (2012)

26. C. Pio, M. Cerqueira, R.M. Harrison, T. Nunes, F. Mirante,C. Alves, C. Oliveira, A. Sanchez de la Campa, B. Artano, M. Matos. Atmos. Environ. 45, 6121 (2011)

27. K.E. Yttri, D. Simpson, R. Bergstrm, G. Kiss, S. Szidat, D. Ceburnis, S. Eckhardt, C. Hueglin, J.K. Njgaard, C. Perrino, I. Pisso, A.S.H. Prevot, J.-P. Putaud, G. Spindler, M. Vana, Zhang, Y-L, Aas, W. Atmos. Chem. Phys. 19, 4211 (2019)

28. S. Sandrini, S. Fuzzi, A. Piazzalunga, P. Prati, P. Bonasoni, F. Cavalli, M.C. Bove, M. Calvello, D. Cappelletti, C. Colombi, D. Contini, G. de Gennaro, A. Di Gilio, P. Fermo, L. Ferrero, V. Gianelle, M. Giugliano, P. Ielpo, G. Lonati, A. Marinoni, D. Massab, U. Molteni, B. Moroni, G. Pavese, C. Perrino, 
M.G. Perrone, M.R. Perrone, J.-P. Putaud, T. Sargolini, R. Vecchi, S. Gilardoni, Atmos. Environ. 99, 587 (2014)

29. World Health Organization World Health Statistics 2019: Monitoring health for the SDGs, edited by WHO (Geneve) (2019)

30. J. Lelievield, J.S. Evans, M. Fnais, D. Giannadaki, A. Pozzer, Nature 525, 367 (2015)

31. F.J. Kelly, J.C. Fussel, Atmos. Environ. 60, 504 (2012)

32. N.A.H. Janssen, A. Yang, M. Strak, M. Steenhof, B. Hellack, M.E. Gerlofs-Nijland, T. Kuhlbusch, F. Kelly, R. Harrison, B. Brunekreef, G. Hoek, F. Cassee, Sci. Total Environ. 472, 572 (2014)

33. N.A.H. Janssen, G. Hoek, M. Simic-Lawson, P. Fischer, L. van Bree, H. ten Brink, M. Keuken, R.W. Atkinson, H.R. Anderson, B. Brunekreef, F.R. Cassee, Environ. Health Perspect. 119(12), 1691 (2011)

34. T.J. Grahame, R.B. Schlesinger, Air Qual. Atmos. Health 3(1), 3(2010)

35. C. Reche, X. Querol, A. Alastuey, M. Viana, J. Pey, T. Moreno, S. Rodrguez, Y. Gonzlez, R. FernndezCamacho, J. de la Rosa, M. Dall'Osto, A.S.H. Prvt, C. Hueglin, R.M. Harrison, P. Quincey, Atmos. Chem. Phys. 11, 6207 (2011)

36. L. Pasteur, Annales de Chimie et de Physique 3, 5 (1890)

37. R.M. Bowers, S. McLetchie, R. Knight, N. Fierer, ISME J. 5, 1 (2010)

38. K.H. Domsch, W. Gams, T. Anderson. Compendium of Soil Fungi, 2nd edition, edited by IHWVerlag (Eching) (2007)

39. B. Ligthart, Aerobiologia 16, 7 (2010)

40. S.M. Burrows, W. Elbert, M.G. Lawrence, U. Poschl, Atmos. Chem. Phys. 9, 9263 (2009)

41. I. Gandolfi, V. Bertolini, R. Ambrosini, G. Bestetti, A. Franzetti, Appl. Microbiol. Biotechnol. 97, 4727 (2013)

42. A.M. Jones, R.M. Harrison, Sci. Total Environ. 326, 151 (2004)

43. C.A. Kellogg, D.W. Griffin, Trends Ecol. Evol. 21(11), 638 (2006)

44. J.H. Seinfeld, Atmospheric chemistry and physics of air pollution, edited by Wiley and Sons (New York) 19XX

45. H. Moosmuller, R.K. Chakrabarty, W.P. Arnott, J. Quant. Spectrosc. Radiat. Transfer 110, 844 (2009)

46. J.G. Watson, J.C. Chow, L.-W.A. Chen, Aerosol Air Qual. Res. 5, 65 (2005)

47. M.E. Birch, R.A. Cary, Aerosol Sci. Technol. 25, 221 (1996)

48. F. Cavalli, J.P. Putaud, M. Viana, K.E. Yttri, J. Gemberg, Atmos. Meas. Tech. 3, 79 (2010)

49. J.C. Chow, J.G. Watson, L.C. Pritchett, W.R. Pierson, C.A. Frazier, R.G. Purcell. Atmos. Environ. 27A(8), 1185 (1993)

50. A. Petzold, M. Schlinner, J. Aerosol Sci. 35, 421 (2004)

51. A. Petzold, J.A. Ogren, M. Fiebig, P. Laj, S.-M. Li, U. Baltensperger, T. Holzer-Popp, S. Kinne, G. Pappalardo, N. Sugimoto, C. Wehrli, A. Wiedensohler, X.-Y. Zhang, Atmos. Chem. Phys. 13, 8365 (2013)

52. A. Petzold, H. Schloesser, P.J. Sheridan, W.P. Arnott, J.A. Ogren, A. Virkkula, Aerosol Sci. Technol. 39, 40-51 (2005)

53. B.J. Turpin, H.-J. Lim, Aerosol Sci. Tecnol. 35(1), 602 (2001)

54. E.R. Graber, Y. Rudich, Atmos. Chem. Phys. 6, 729 (2006)

55. M.O. Andreae, A. Gelencsr, Atmos. Chem. Phys. 6, 3131 (2006)

56. J. Yan, X. Wang, P. Gong, C. Wang, Z. Cong, Sci. Total Environ. 634, 1475 (2018)

57. J.M. Haywood, K.P. Shine, Geophys. Res. Lett. 22(5), 603 (1995)

58. S. Manish, C.D. Cappa, J. Fan, A.H. Goldstein, A.B. Guenther, J.L. Jimenez, C. Kuang, A. Lasking, S.T. Martin, N. Lee Ng, T. Petaja, J.R. Pierce, P.J. Rasch, P. Roldin, J.H. Seinfeld, J. Shilling, J.N. Smith, J.A. Thornton, R. Volkamer, J. Wang, D.R. Worsnop, R.A. Zaveri, A. Zelenyuk, Q. Zhang, Rev. Geophys. 55(2), 509 (2017)

59. S. Fuzzi, U. Baltensberger, K. Carslaw, S. Decesari, H. Denier van der Gon, M.C. Facchini, D. Fowler, I. Koren, B. Langford, U. Lohmann, E. Nemitz, S. Pandis, I. Riipinen, Y. Rudich, M. Schaap, J. Slowik, D.V. Spracklen, E. Vignati, M. Wild, M. Williams, S. Gilardoni, Atmos. Chem. Phys. 15, 8217 (2015)

60. F. Costabile, H. Alas, M. Aufderheide, P. Avino, F. Amato, S. Argentini, F. Barnaba, M. Berico, V. Bernardoni, R. Biondi, G. Casasanta, S. Ciampichetti, G. Calzolai, S. Canepari, A. Conidi, E. Cordelli, A. Di Ianni, L. Di Liberto, M.C. Facchini, A. Facci, D. Frasca, S. Gilardoni, M.G. Grollino, M. Gualtieri, F. Lucarelli, A. Malaguti, M. Manigrasso, M. Montagnoli, S. Nava, C. Perrino, E. 
Padoan, I. Petenko, X. Querol, G. Simonetti, G. Tranfo, S. Ubertini, G. Valli, S. Valentini, R. Vecchi, F. Volpi, K. Weinhold, A. Wiedensohler, G. Zanini, G.P. Gobbi, E. Petralia, Atmosphere 8, 249 (2017)

61. H. Olstrup, C. Johansson, B. Forsberg, Int. J. Environ. Res. Public Health 13, 249 (2016)

62. P. Quincey, Atmos. Environ. 41, 7964 (2007)

63. D. Segersson, K. Eneroth, L. Gidhagen, C. Johansson, G. Omsted, A.E. Nyln, B. Forsberg, Int. J. Environ. Res. Public Health 14, 742 (2017)

64. D.Z. Zhang, J. Grigg, S. George, O.H. Teoh, O.M. Chay, A. Pugalenthi, P. Wong, B. Thomas, Eur. Respir. J. 46, 3409 (2015)

65. A. Tobias, A. Karanasiou, C. Reche, F. Amato, A. Alasuey, X. Querol, Eur. Respir. J. 44, 2923 (2014)

66. S. Moroni, A.A. Ruprecht, G. Tosti, B. Villavecchia, G. Mocknik, C. Sioutas, D. Westerdahl, G. Invernizzi, Eur. Respir. J. 42, 1010 (2013)

67. A.A. Ruprecht, G. Invernizzi, C. De Marco, R. Mazza, G. Mocknik, C. Sioutas, D. Westerdahl, Eur. Respir. J. 38, 4207 (2011)

68. N.A.H. Janssen, M.E. Gerlofs-Nijland, T. Lanki, R.O. Salonen, F. Cassee, G. Hoek, P. Fisher, B. Brunekreef, M. Krzyzanowski. Health effects of Black Carbon, edited by WHO, Regional Office for Europe (Copenaghen) (2012)

69. J.L. Mauderly, J.C. Chow, Inhal. Toxicol. 20, 257-288 (2008)

70. The International Commission on Radiological ProtectionPublication 103 , The 2007 Recommendations of the International Commission on Radiological Protection, edited by Valentin, J. (Orlando) (2007)

71. P. Amato, M. Joly, C. Schaupp, E. Attard, O. Mhler, C.E. Morris, Y. Brunet, A.M. Delort, Atmos. Chem. Phys. 15, 6455 (2015)

72. P. Brotto, B. Repetto, P. Formenti, E. Pangui, A. Livet, N. Bousserrhine, I. Martini, O. Varnier, J.-F. Doussin, P. Prati, Aerobiologia 31, 445 (2015)

73. B.J. Finlayson-Pitts, J.N. Pitts. Chemistry of the upper and lower atmosphere: Theory, experiments and applications, edited by Academic Press (San Diego) (2000)

74. P. Du, Z. Lu, W. Ren, P. Fu, Aerosol Air Qual. Res. 18, 444 (2018)

75. T.C. Bond, S.J. Doherty, D.W. Fahey, P.M. Forster, T. Berntsen, B.J. DeAngelo, M.G. Flanner, S. Ghan, B. Krcher, B.D. Koch, S. Kinne, Y. Kondo, P.K. Quinn, M.C. Sarofim, M.G. Schultz, M. Schulz, C. Venkataraman, H. Zhang, S. Zhang, N. Bellouin, S.K. Guttikunda, P.K. Hopke, M.Z. Jacobson, J.W. Kaiser, Z. Klimont, U. Lohmann, J.P. Schwarz, D. Shindell, T. Storelvmo, S.G. Warren, C.S. Zender, J. Geophys. Res. Atmos. 118, 5380 (2013)

76. P. Forster, et al., Changes in atmospheric constituents and in radiative forcing, in Climate Change 2007: The Physical Science Basis. Contribution of Working Group I to the Fourth Assessment Report of the Intergovernmental Panel on Climate Change, edited by S. Solomon, D. Qin, M. Manning, Z. Chen, M. Marquis, K.B. Averyt, M. Tignor, H. Miller, Cambridge University Press (New York) (2007)

77. H. Matsui, D.S. Hamilton, N.M. Mahowald, Nat. Commun. 9, 3446 (2018)

78. S. Ramachandran, S.G. Kedia, J. Geophys. Res. D 115, 10202 (2010)

79. D. Jacob, D. Winner, Atmos. Environ. 43, 51 (2009)

80. J. Frhlich-Nowoisky, C.J. Kampf, B. Weber, J.A. Huffman, C. Phlker, M.O. Andreae, N. Lang-Yona, S.M. Burrows, S.S. Gunthe, W. Elbert, H. Su, P. Hoor, E. Thines, T. Hoffmann, V.R. Desprs, U. Pschl, Atmos. Res. 182, 346 (2016)

81. D. Sands, V. Langhans, A. Scharen, G. De Smet, Idojaras 86, 148 (1982)

82. D.K. Hall, J. Martinec. Remote sensing of ice and snow, edited by Chapman and Hall Ltd. (London) (1985)

83. S.G. Warren, W.J. Wiscombe, Nature 313, 467 (1985)

84. M. Tedesco, S. Doherty, X. Fettweis, P. Alexander, J. Jeyaratnam, J. Stroeve, The Cryosphere 10, 477 (2016)

85. C.E. Bggild, R.E. Brandt, K.J. Brown, S.G. Warren, J. Glaciol. 56, 101 (2010)

86. J.C. Ryan, A. Hubbard, M. Stibal, T.D. Irvine-Fynn, J. Cook, L.C. Smith, K. Cameron, J. Box, Nat. Commun. 9, 1065 (2018)

87. N. Takeuchi, S. Kohshima, K. Seko, Arctic. Antarctic Alpine Res. 33, 115 (2001)

88. J. Cook, A. Edwards, N. Takeuchi, T. Irvine-Fynn, Prog. Phys. Geogr. Earth Environ. 40, 66 (2015)

89. G. Baccolo, B. Di Mauro, D. Massab, M. Clemenza, M. Nastasi, B. Delmonte, M. Prata, P. Prati, E. Previtali, V. Maggi, Sci. Rep. 7, 9623 (2017) 
90. G. Baccolo, okas, E., Gaca, P., Massab, D., Ambrosini, R., Azzoni, R.S., Clason, C., Di Mauro, B., Franzetti, A., Nastasi, M., Prata, M., Prati, P., Previtali, E., Delmonte, B., Maggi, V., J. Cryosphere 14, 657 (2020)

91. A.L. Khan, S. Wagner, R. Jaffe, P. Xian, M. Williams, R. Armstrong, D. McKnight, Geophys. Res. Lett. 44, 6226 (2017)

92. T. Dittmar, Org. Geochem. 39(4), 396 (2008)

93. S. Brighenti, M. Tolotti, M.C. Bruno, G. Wharton, M.T. Pusch, W. Bertoldi, Sci. Total Environ. 675, 542 (2019)

94. I. Palomo, Mt. Res. Dev. 37(2), 179 (2017)

95. S. Kang, Y. Xu, Q. You, W.-A. Flügel, N. Pepin, T. Yao, Environ. Res. Lett. 5, 015101 (2010)

96. A. Gobiet, S. Kotlarski, M. Beniston, G. Heinrich, J. Rajczak, M. Stoffel, Sci. Total Environ. 493, 1138 (2014)

97. World Meteorological Organization. Manual on the Global Observing System, Volume I Global Aspects, World Meteorological Organization, edited by WMO (Geneva) (2015)

98. J.H. Seinfeld, Atmospheric chemistry and physics of air pollution, edited by Wiley and Sons (New York) (1986)

99. D. Founda, S. Kazadzis, N. Mihalopoulos, E. Gerasopoulos, M. Lianou, P.I. Raptis, Atmos. Chem. Phys. 16, 11219 (2016)

100. J.C. Trijonis, W.C. Malm, M. Pitchford, W. H. White, R. Charlson, R. Husar. Visibility existing and historical conditions causes and effects, Report 24, edited by National Acid Precipitation Assessment Program (Washington DC) (1990)

101. W.C. Malm, Introduction to Visibility, edited by Cooperative Institute for Research in the Atmosphere (Fort Collins) (1999)

102. J.F. Sisler, D. Huffman, D.A. Latimer. Spatial and temporal patterns and the chemical composition of the haze in the United States: An Analysis of Data from the IMPROVE Network,1988-1991, edited by Environmental Protection Agency (Las Vegas) (1993)

103. A. Singh, W.J. Bloss, F.D. Pope, Atmos. Chem. Phys. 17, 2085 (2017)

104. M. Iqbal, An Introduction to solar radiation, edited by Academic Press (Toronto) (1983)

105. D. Massab, V. Bernardoni, M.C. Bove, A. Brunengo, E. Cuccia, A. Piazzalunga, P. Prati, G. Valli, R. Vecchi, J. Aerosol Sci. 60, 34 (2013)

106. M.Z. Jacobson, Atmospheric pollution: history, science, and regulation, edited by Cambridge University Press (New York) (2002)

107. A. Singh, S. Dey, Atmos. Environ. 62, 367 (2012)

108. N.P. Hyslop, Atmos. Environ. 43, 182 (2009)

109. J.M. Langridge, D. Lack, C.A. Brock, R. Bahreini, A.M. Middlebrook, J.A. Neuman, J.B. Nowak, A.E. Perring, J.P. Schwarz, J.R. Spackman, J.S. Holloway, I.B. Pollack, T.B. Ryerson, J.M. Roberts,

C. Warneke, J.A. de Gouw, M.K. Trainer, D.M. Murphy, J. Geophys. Res. 17, 11 (2012)

110. P. Brimblecombe. The Effects of Air Pollution on the Built Environment. Air Pollution Reviews., edited by mperial College Press (London) (2003)

111. P.A. Baedecker, M.M. Reddy, K.J. Reimann, C.A. Sciammarella, Atmos. Environ. 26B, 147 (1992)

112. A. Bonazza, C. Sabbioni, N. Ghedini, Atmos. Environ. 39, 2607 (2005)

113. A. Bernardi, D. Camuffo, M. Del Monte, C. Sabbioni, Sci. Total Environ. 46, 243 (1985)

114. R.H.M. Godoi, K. Kontozova, R. Van Grieken, Atmos. Environ. 40, 1255 (2006)

115. S. Nava, F. Becherini, A. Bernardi, A. Bonazza, M. Chiari, I. Garc-Orellana, F. Lucarelli, N. Ludwig, A. Migliori, C. Sabbioni, R. Udisti, G. Valli, R. Vecchi, Sci. Total Environ. 408, 1403 (2010)

116. M. Viana, T.A.J. Kuhlbusch, X. Querol, A. Alastuey, R.M. Harrison, P.K. Hopke, W. Winiwarter, M. Vallius, S. Szidat, A.S.H. Prvt, C. Hueglin, H. Bloemen, P. Whlin, R. Vecchi, A.I. Miranda, A. Kasper-Giebl, W. Maenhaut, R. Hitzenberger, J. Aerosol Sci. 39, 827 (2008)

117. A. Eldering, G.R. Cass, J. Geophys. Res. 101, D14 (1996)

118. J.G. Watson, T. Zhu, J.C. Chow, J. Engelbrecht, E.M. Fujita, W.E. Wilson, Chemosphere 49, 1093 (2002)

119. P.K. Hopke, K. Ito, T. Mar, W.F. Christensen, D.J. Eatough, R.C. Henry, R.C. Henry, E. Kim, F. Laden, R. Lall, T.V. Larson, H. Liu, L. Neas, J. Pinto, M. Stlzel, H. Suh, P. Paatero, G.D. Thurston, J. Eposure Sci. Environ. Epidemiol. 16, 257 (2006)

120. C.A. Belis, F. Karagulian, F. Amato, M. Almeida, P. Artaxo, D.C.S. Beddows, V. Bernardoni, M.C. Bove, S. Carbone, D. Cesari, D. Contini, E. Cuccia, E. Diapouli, K. Eleftheriadis, O. Favez, I. El Haddad, R.M. Harrison, S. Hellebust, J. Hovorka, E. Jang, H. Jorquera, T. Kammermeier, M. Karl, F. 
Lucarelli, D. Mooibroek, S. Nava, J.K. Nojgaard, P. Paatero, M. Pandolfi, M.G. Perrone, J.E. Petit, A. Pietrodangelo, P. Pokorna, P. Prati, A.S.H. Prevot, U. Quass, X. Querol, D. Saraga, J. Sciare, A. Sfetsos, G. Valli, R. Vecchi, M. Vestenius, E. Yubero, P.K. Hopke, Atmos. Environ. 123, 240 (2015)

121. C.A. Belis, D. Pernigotti, G. Pirovano, O. Favez, J.L. Jaffrezo, J. Kuenen, H.D. van Der Gon, M. Reizer, V. Riffault, L.Y. Alleman, M. Almeida, F. Amato, A. Angyal, G. Argyropoulos, S. Bande, I. Beslic, J.-L. Besombes, M.C. Bove, P. Brotto, G. Calori, D. Cesari, C. Colombi, D. Contini, G. De Gennaro, A. Di Gilio, E. Diapouli, I. El Haddad, H. Elbern, K. Eleftheriadis, J. Ferreira, M.G. Vivanco, S. Gilardoni, B. Golly, S. Hellebust, P.K. Hopke, Y. Izadmanesh, H. Jorquera, K. Krajsek, R. Kranenburg, P. Lazzeri, F. Lenartz, F. Lucarelli, K. Maciejewska, A. Manders, M. Manousakas, M. Masiol, M. Mircea, D. Mooibroek, S. Nava, D. Oliveira, M. Paglione, M. Pandolfi, M. Perrone, E. Petralia, A. Pietrodangelo, S. Pillon, P. Pokorna, P. Prati, D. Salameh, C. Samara, L. Samek, D. Saraga, S. Sauvage, M. Schaap, F. Scotto, K. Sega, G. Siour, R. Tauler, G. Valli, R. Vecchi, E. Venturini, M. Vestenius, A. Waked, E. Yubero, Atmos. Environ. X5, 100053 (2020)

122. H. Simon, L. Beck, P.V. Bhave, F. Divita, Y. Hsu, D. Luecken, J.D. Mobley, G.A. Pouliot, A. Reff, G. Sarwar, M. Strum, Atmos. Pollut. Res. 1(4), 206 (2010)

123. D. Pernigotti, C.A. Belis, L. Span, Atmos. Pollut. Res. 7, 304 (2016)

124. P. Pant, Z. Shi, F.D. Pope, R.M. Harrison, Aerosol Air Qual. Res. 17(1), 117 (2017)

125. S. Pervez, S. Bano, J.G. Watson, J.C. Chow, J.L. Matawle, A. Shrivastava, S. Tiwari, Y.F. Pervez, Aerosol Air Qual. Res. 18(7), 1660 (2018)

126. M.C. Bove, P. Brotto, F. Cassola, E. Cuccia, D. Massab, A. Mazzino, A. Piazzalunga, P. Prati, Atmos. Environ. 94, 274 (2014)

127. J.T. Wilkerson, M.Z. Jacobson, A. Malwitz, S. Balasubramanian, R. Wayson, G. Fleming, A.D. Naiman, S.K. Lele, Atmos. Chem. Phys. 10, 6391 (2010)

128. L.T. Ogundele, O.K. Owoade, F.S. Olise, P.K. Hopke, Environ. Monit. Assess. 188, 574 (2016)

129. D. Contini, D. Cesari, M. Conte, A. Donateo, Sci. Total Environ. 131, 560-561 (2016)

130. J. Sun, S. Shen, Y. Zhang, Q. Zhang, Y. Lei, Y. Huang, X. Niu, H. Xu, J. Cao, S.S.H. Ho, X. Li, Atmos. Environ. 205, 36 (2019)

131. P. Paatero, J. Comput. Graph. Stat. 8(4), 854 (1999)

132. A.C. Forello, V. Bernardoni, G. Calzolai, F. Lucarelli, D. Massab, S. Nava, R.E. Pileci, P. Prati, S. Valentini, G. Valli, R. Vecchi, Atmos. Chem. Phys. 19, 11235 (2019)

133. U. Poschl, Atmos. Chem. 375, 30 (2003)

134. K.H. Homann, Angew. Chem. 37, 2435 (1998)

135. A. Sadezky, H. Muckenhuber, H. Grothe, R. Niessner, U. Pschl, Carbon 43, 1731 (2005)

136. J.T. Jayne, D.C. Leard, X. Zhang, P. Davidovits, K.A. Smith, C.E. Kolb, D.R. Worsnop. Aerosol Sci. Technol. 33(1-2), 49 (2000)

137. E. Weingartner, H. Saatho, M. Schnaiter, N. Streit, B. Bitnar, U. Baltensperger, J. Aerosol Sci. 34, 1445 (2003)

138. W.P. Arnott, K. Hamasha, H. Moosmuller, P.J. Sheridan, J.A. Ogren, Aerosol Sci. Technol. 39, 17 (2006)

139. O. Schmid, P. Artaxo, W.P. Arnott, D. Chand, L.V. Gatti, G.P. Frank, A. Hoffer, M. Schnaiter, M.O. Andrea, Atmos. Chem. Phys. 6, 3443 (2006)

140. A. Virkkula, T. Makela, R. Hillamo, T. Yli-Tuomi, A. Hirsikko, K. Hameri, I.K. Koponen, J. Air Waste Manag. Assoc. 57, 1214 (2007)

141. M. Collaud Coen, E. Weingartner, A. Apituley, D. Ceburnis, R. Fierz-Schmidhauser, H. Flentje, J.S. Henzing, S.G. Jennings, M. Moerman, A. Petzold, O. Schmid, U. Baltensperger, Atmos. Meas. Tech. 3, 457 (2010)

142. J. Saturno, C. Phlker, D. Massab, J. Brito, S. Carbone, Y. Cheng, X. Chi, F. Ditas, I.H. Angelis, D. Morn-Zuloaga, M.L. Phlker, L. Rizzo, V., Walter, D., Wang, Q., Artaxo, P., Prati, P., Andreae, M.O. , Atmos. Meas. Tech. 10, 2837 (2017)

143. C. Liousse, H. Cachier, S.G. Jennings, Atmos. Environ. 27A, 1203 (1993)

144. G. Hnel, Beitrge zur Physik der Atmosphre 60, 241 (1987)

145. H.C. Van de Hulst, Multiple light scattering, Vol I + II, edited by Academic Press (New York) (1980)

146. D. Massab, L. Caponi, V. Bernardoni, M.C. Bove, P. Brotto, G. Calzolai, F. Cassola, M. Chiari, M.E. Fedi, Giannoni Fermo, P.M., Lucarelli, F., Nava, S., Piazzalunga, A., Valli, G., Vecchi, R., Prati, P., Atmos. Environ. 1, 1081 (2015)

147. E. Filippi, P. Prati, A. Zucchiatti, V. Ariola, P. Corvisiero, F. Lucarelli, P.A. Mand, Nuclear Instrum. Methods Phys. Res. B150, 370 (1999) 
148. N.K. Kumar, J.C. Corbin, E.A. Bruns, D. Massab, J.G. Slowik, L. Drinovec, G. Mocnik, P. Prati, A. Vlachou, U. Baltensperger, M. Gysel, I. El-Haddad, A.S.H. Prvt, Atmos. Chem. Phys. 18, 17843 (2018)

149. J.C. Corbin, S.M. Pieber, H. Czech, M. Zanatta, G. Jakobi, D. Massab, J. Orasche, I. El-Haddad, A.A. Mensah, B. Stengel, L. Drinovec, G. Mocnik, R. Zimmermann, A.S.H. Prvt, M. Gysel, J. Geophys. Res. Atmos. 12, 36175 (2018)

150. J.C. Corbin, A.A. Mensah, Orasche Pieber, J., Michalke, B., Zanatta, M., Massab, D., Buatier de Mongeot, F., Mennucci, C., El-Haddad, I, Kumar, N., Stengel, B., Huang, Y., Zimmermann, R., Prvt, A.S.H., Gysel, M. , Environ. Sci. Technol. 52, 6714 (2018)

151. J.C. Corbin, H. Czech, D. Massab, F. Buatier de Mongeot, G. Jakobi, F. Liu, P. Lobo, C. Mennucci, A.A. Mensah, J. Orasche, Prvt Pieber, A.S.H., Stengel, B., Tay, L.L., Zanatta, M., Zimmermann, R., El-Haddad, Gysel, M. , NPJ Clim. Atmos. Sci. 2, 12 (2019)

152. M.M. Scerri, K. Kandler, S. Weinbruch, E. Yubero, N. Galindo, P. Prati, L. Caponi, D. Massab, Chemosphere 211, 465 (2018)

153. R. Vecchi, V. Bernardoni, C. Paganelli, G. Valli, J. Aerosol Sci. 70, 15 (2014)

154. V. Bernardoni, G. Valli, R. Vecchi, J. Aerosol Sci. 107, 84 (2017)

155. J.J. Huntzicker, R.L. Johnson, J.J. Shah, R.A. Cary, Particulate Carbon Atmos. Life Cycle 375, 79 (1982)

156. D. Gustafsson, T.D. Bucheli, Z. Kukulska, M. Andersson, C. Largeau, J.N. Rouzaud, C.M. Reddy, T.I. Eglinton, Global Biogeochem. Cycles 15, 881 (2001)

157. R. Vecchi, G. Valli, P. Fermo, DAlessandro, A., Piazzalunga, A., Bernardoni, V. , Atmos. Environ. 43, 1713 (2009)

158. D. Massab, A. Altomari, V. Vernocchi, P. Prati, Atmos. Meas. Tech. 12, 3173 (2019)

159. J.C. Chow, J.Z. Yu, J.G. Watson, S.S. Hang, T.L. Bohannan, M.D. Hays, K.K. Fung, J. Environ. Sci. Health Part A42, 1521 (2007)

160. Y. Wang, A. Chung, S.E. Paulson, Atmos. Chem. Phys. 10, 1147 (2010)

161. B.J. Turpin, R.A. Cary, J.J. Huntzicker, Aerosol Sci. Technol. 12, 161 (1990)

162. L.-W.A. Chen, J.C. Chow, J.G. Watson, B.A. Schichtel, Atmos. Meas. Tech. 5, 2329 (2012)

163. L.-W.A. Chen, J.C. Chow, X.L. Wang, J.A. Robles, B.J. Sumlin, D.H. Lowenthal, R. Zimmermann, J.G. Watson, Atmos. Meas. Tech. 8, 451 (2015)

164. J.C. Chow, J.G. Watson, D. Crow, D.H. Lowenthal, T. Merrifield, Aerosol Sci. Technol. 34, 23 (2001)

165. J.M. Conny, D.B. Klinedienst, S.A. Wight, J.L. Paulsen, Aerosol Sci. Technol. 37, 703 (2003)

166. J.C. Chow, J.G. Watson, L.-W.A. Chen, W.P. Arnott, H. Moosmller, Environ. Sci. Technol. 38, 4414 (2003)

167. G. Zhi, Y. Chen, G. Sheng, J. Fu, Environ. Monit. Assess. 154, 253 (2009)

168. M. Giannoni, G. Calzolai, M. Chiari, A. Cincinelli, F. Lucarelli, T. Martellini, S. Nava, Sci. Total Environ. 571, 195 (2016)

169. H. ten Brink, W. Maenhaut, R. Hitzenberger, T. Gnauk, G. Spindler, A. Even, X. Chi, H. Bauer, H. Puxbaum, J.-P. Putaud, J. Tursic, A. Berner, Atmos. Environ. 38, 6507 (2004)

170. W. Maenhaut, M. Claeys, J. Vercauteren, E. Roekens. Abstract Book of the 10th International Conference on Carbonaceous Particles in the Atmosphere (ICCPA)F, p. 6 (2011)

171. K. Fung, Aerosol Sci. Technol. 12, 122 (1990)

172. R. Subramanian, A.Y. Khlystov, A.L. Robinson, Aerosol Sci. Technol. 40, 763 (2006)

173. A. Piazzalunga, V. Bernardoni, P. Fermo, G. Valli, R. Vecchi, Atmos. Chem. Phys. 11, 10193 (2011)

174. P. Panteliadis, T. Hafkenscheid, B. Cary, E. Diapouli, A. Fischer, O. Favez, P. Quincey, M. Viana, R. Hitzenberger, R. Vecchi, D. Saraga, J. Sciare, J.L. Jaffrezo, A. John, J. Schwarz, M. Giannoni, J. Novak, A. Karanasiou, P. Fermo, W. Maenhaut, Atmos. Meas. Tech. 8, 779 (2015)

175. J.C. Chow, X. Wang, B.J. Sumlin, S.B. Gronstal, L.-W.A. Chen, D.L. Trimble, S.D. Kohl, S.R. Mayorga, G. Riggio, P.R. Hurbain, M. Johnson, R. Zimmermann, J.G. Watson, Aerosol Air Qual. Res. 15, 1145 (2015)

176. D. Massab, L. Caponi, M.C. Bove, P. Prati, Atmos. Environ. 125, 119 (2016)

177. J.C. Chow, J.G. Watson, M.C. Green, X. Wang, L.-W.A. Chen, D.L. Trimble, P.M. Cropper, S.D. Kohl, S.B. Gronstal, J. Air Waste Manag. Assoc. 68, 494 (2018)

178. Z. Bozki, A. Pogny, G. Szab, Appl. Spectrosc. Rev. 46, 1 (2011)

179. A. Petzold, R. Niessner, Appl. Phys. B 63, 191 (1996)

180. X. Guo, T. Nakayama, H. Yamada, S. Inomata, K. Tonokura, Y. Matsumi, Atmos. Environ. 94, 428 (2014) 
181. D. Al Fischer, G.D. Smith, Aerosol Sci. Technol. 52, 393 (2018)

182. T.L. Anderson, D.S. Covert, J.D. Wheeler, J.M. Harris, K.D. Perry, B.E. Trost, D.J. Jaffe, J.A. Ogren, J. Geophys. Res. 104, 26793 (1999)

183. J.W. Cremer, P.A. Covert, E.A. Parmentier, R. Signorell, J. Phys. Chem. Lett. 8, 3398 (2017)

184. K.A. Simon, T. Ajtai, G. Gulyaas, N. Utry, M. Pinter, G. Szabo, Z. Bozoki, J. Aerosol Sci. 104, 10 (2016)

185. Z. Yu, J. Assif, G. Magoon, P. Kebabian, W. Brown, W. Rundgren, J. Peck, R. Miake-Lye, D. Liscinsky, B. True, Aerosol Sci. Technol. 51, 1438 (2017)

186. J.M. Langridge, M.S. Richardson, D.A. Lack, C.A. Brock, D.M. Murphy, Aerosol Sci. Technol. 47, 1163 (2013)

187. J.P. Schwarz, R.S. Gao, D.W. Fahey, D.S. Thomson, L.A. Watts, J.C. Wilson, J.M. Reeves, M. Darbeheshti, D.G. Baumgardner, G.L. Kok, S.H. Chung, M. Schulz, J. Hendricks, A. Lauer, B. Krcher, J.G. Slowik, K.H. Rosenlof, T.L. Thompson, A.O. Langford, M. Loewenstein, K.C. Aikin, J. Geophys. Res. 111, 16207 (2006)

188. J.P. Schwarz, J.R. Spackman, D.W. Fahey, R.S. Gao, U. Lohmann, P. Stier, L.A. Watts, D.S. Thomson, D.A. Lack, L. Pfister, M.J. Mahoney, D. Baumgardner, J.C. Wilson, J.M. Reeves, J. Geophys. Res. 113, D03203 (2008)

189. N. Moteki, Y. Kondo, Aerosol Sci. Technol. 44, 663 (2010)

190. J.G. Slowik, E.S. Cross, J.-H. Han, P. Davidovits, T.B. Onasch, J.T. Jayne, L.R. Williams, M.R. Canagaratna, D.R. Worsnop, T.K. Chakrabarty, J. Moosmller, E.P. Arnott, J.P. Schwarz, R.-S. Gao, F.W. Fahey, G.L. Kok, A. Petzold, Aerosol Sci. Technol. 41, 295 (2007)

191. Y. Kondo, L. Sahu, N. Moteki, F. Khan, N. Takegawa, X. Liu, M. Koike, T. Miyakawa, Aerosol Sci. Technol. 45, 295 (2011)

192. M. Laborde, M. Schnaiter, C. Linke, H. Saathoff, K.-H. Naumann, O. Mhler, S. Berlenz, U. Wagner, J.W. Taylor, D. Liu, M. Flynn, J.D. Allan, H. Coe, K. Heimerl, F. Dahlktter, B. Weinzierl, A.G. Wollny, M. Zanatta, J. Cozic, P. Laj, R. Hitzenberger, J.P. Schwarz, M. Gysel, Atmos. Meas. Tech. 3, 3077 (2012)

193. D. Liu, J. Whitehead, M.R. Alfarra, E. Reyes-Villegas, D.V. Spracklen, C.L. Reddington, S. Kong, P.I. Williams, Y.-C. Ting, S. Haslett, J.W. Taylor, M.J. Flynn, W.T. Morgan, G. McFiggans, H. Coe, J.D. Allan, Nat. Geosci. 10, 184 (2017)

194. G. Motos, J.C. Corbin, J. Schmale, R.L. Modini, M. Bert, P. Kupiszewski, U. Baltensperger, M. Gyseleer, Geophys. Res. Lett. 47, 8011 (2020)

195. J.C. Corbin, M. Gysel-Beer, Atmos. Chem. Phys. 19, 15673 (2019)

196. N. Moteki, Y. Kondo, Aerosol Sci. Technol. 44, 663 (2010)

197. M. Laborde, P. Mertes, P. Zieger, J. Dommen, U. Baltensperger, M. Gysel-Beer, Atmos. Meas. Tech. 5, 1031 (2012)

198. J.P. Schwarz, R.S. Gao, J.R. Spackman, L.A. Watts, D.S. Thomson, D.W. Fahey, T.B. Ryerson, J. Peischl, J.S. Holloway, M. Trainer, G.J. Frost, T. Baynard, D.A. Lack, J.A. de Gouw, C. Warneke, L.A. Del Negro, Geophys. Res. Lett. 35, L13810 (2008)

199. M. Shiraiwa, Y. Kondo, N. Moteki, N. Takegawa, L.K. Sahu, A. Takami, S. Hatakeyama, S. Yonemura, D.R. Blake, J. Geophys. Res. 113, D24210 (2008)

200. T.B. Onasch, P. Massoli, P.L. Kebabian, F.B. Hills, F.W. Bacon, A. Freedman, Aerosol Sci. Technol. 49, 267 (2015)

201. P. Massoli, P.L. Kebabian, T.B. Onasch, F.B. Hills, A. Freedman, Aerosol Sci. Technol. 44, 428 (2010)

202. A. Petzold, T. Onasch, P. Kebabian, A. Freedman, Atmos. Meas. Tech. 6, 1141 (2013)

203. J. Perim de Faria, U. Bundke, A. Freedman, T. B. Onasch, A. Petzold, Atmos. Meas. Tech. Discuss. 49, 146 (2019)

204. M.A.C. Potenza, T. Sanvito, S. Argentiere, C. Cella, B. Paroli, C. Lenardi, P. Milani, Sci. Rep. 5, $18228(2015)$

205. M.A.C. Potenza, T. Sanvito, A. Pullia, AIP Adv. 5, 117222 (2015)

206. F. Mariani, V. Bernardoni, F. Riccobono, R. Vecchi, G. Valli, T. Sanvito, B. Paroli, A. Pullia, M.A.C. Potenza, J. Nanopart. Res. 19, 291 (2017)

207. W.F. Libby. Radiocarbon dating, edited by University Chicago Press (Chicago) (1952)

208. G. Clayton, J. Arnold, F. Patty, Science 122, 751 (1955)

209. R.A. Muller, Science 196, 489 (1977)

210. L.A. Currie, Radiocarbon 42(1), 115 (2000)

211. I. Levin, B. Kromer, M. Schmidt, H. Sartorius, Geophys. Res. Lett. 30(23), 2194 (2003) 
212. C.W. Lewis, G.A. Klouda, W.D. Ellenson, Atmos. Environ. 38, 6053 (2004)

213. S. Szidat, T.M. Jenk, H.W. Gggeler, H.-A. Synal, R. Fisseha, U. Baltensperger, M. Kalberer, V. Samburova, S. Reimann, I. Hajdas, Atmos. Environ. 38, 4035 (2004)

214. S. Szidat, T.M. Jenk, H.-A. Synal, M. Kalberer, L. Wacker, I. Hajdas, A. Kasper-Giebl, U. Baltensperger, J. Geophys. Res. 111, D07206 (2006)

215. H.-A. Synal, S. Jacob, M. Suter, Nucl. Instrum. Methods Phys. Res. B172, 1 (2000)

216. A. Piazzalunga, P. Fermo, V. Bernardoni, R. Vecchi, G. Valli, M.A. De Gregorio, Int. J. Environ. Anal. Chem. 90(12), 934 (2010)

217. M.E. Fedi, A. Cartocci, M. Manetti, F. Taccetti, P.A. Mand, Nucl. Instrum. Methods Phys. Res. B259, 18 (2007)

218. G. Calzolai, V. Bernardoni, M. Chiari, M.E. Fedi, F. Lucarelli, S. Nava, F. Riccobono, F. Taccetti, G. Valli, R. Vecchi, Nucl. Instrum. Methods Phys. Res. B269, 203 (2011)

219. L. Wacker, S.M. Fahrni, I. Hajdas, M. Molnar, H.-A. Synal, S. Szidat, Y.L. Zhang, Nucl. Instrum. Methods Phys. Res. B294, 315 (2013)

220. S. Szidat, G.A. Salazar, E. Vogel, M. Battaglia, L. Wacker, H.A. Synal, A. Trler, Radiocarbon 56(2), 561 (2014)

221. W.D. Griffiths, G.A.L. Decosemo, J. Aerosol Sci. 25, 1425 (1994)

222. H. Mbareche, E. Brisebois, M. Veillette, C. Duchaine, Sci. Total Environ. 2095, 599-600 (2017)

223. M.C. Chi, C.S. Li, Aerosol Sci. Technol. 41, 672 (2007)

224. C. Phlker, A. Huffman, U. Pschl, Atmos. Meas. Tech. 5, 37 (2012)

225. J.A. Huffman, J.L. Santarpia, Online techniques for quantification and characterization of biological aerosol, in: Microbiology of Aerosols, edited by A.M. Delort, P. Amato, for J. Wiley and Sons (New York) (2017)

226. S.C. Hill, R.G. Pinnick, S. Niles, N.F. Fell, Y.L. Pan, J. Bottiger, B.V. Bronk, S. Holler, R.K. Chang, Appl. Opt. 40, 3005 (2001)

227. A.E. Perring, J.P. Schwarz, D. Baumgardner, M.T. Hernandez, D.V. Spracklen, C.L. Heald, R.S. Gao, G. Kok, G.R. McMeeking, J.B. McQuaid, D.W. Fahey, J. Geophys. Res. Atmos. 120, 1153 (2015)

228. N.J. Savage, C.E. Krentz, T. Knemann, T.T. Han, G. Mainelis, C. Phlker, A. Huffman, Atmos. Meas. Tech. 10, 4279 (2017)

229. T.W. Kirchstetter, T. Novakok, P.V. Hobbs, J. Geophys. Res. 109, D21208 (2004)

230. K. Lewis, W.P. Arnott, H. Moosmller, C.E. Wold, J. Geophys. Res. 113, D16203 (2008)

231. N. Utry, T. Ajtai, Pintr Filep, M., Trk, Zs., Bozki, Z., Szab, G. , Atmos. Environ. 91,52 (2014)

232. D.A. Lack, J.M. Langridge, Atmos. Chem. Phys. 13, 10535 (2013)

233. J. Sandradewi, A.H. Prevot, S. Szidat, N. Perron, M. Rami Alfarra, V. Lanz, E. Weingartner, U. Baltensperger, Environ. Sci. Technol. 42, 3316 (2008)

234. O. Favez, I. El Haddad, C. Piot, A. Boreave, E. Abidi, N. Marchand, J.L. Jaffrezo, J.L. Besombes, M.B. Personnaz, J. Sciare, H. Wortham, C. Geroge, Atmos. Chem. Phys. 10, 5295 (2010)

235. L.W.A. Chen, J.C. Chow, X.L. Wang, J.A. Robles, B.J. Sumlin, D.H. Lowenthal, R. Zimmermann, J.G. Watson, Atmos. Meas. Tech. 8, 451 (2015)

236. V. Bernardoni, R.E. Pileci, L. Caponi, D. Massab, Atmosphere 8, 218 (2017)

237. M. Gyawali, W.P. Arnott, K. Lewis, H. Moosmller, Atmos. Chem. Phys. 9, 8007 (2009)

238. A. Laskin, J. Laskin, S.A. Nizkorodov, Chem. Rev. 115(10), 4335 (2015)

239. M.R. Gwinn, V. Vallyathan, Environ. Health Perspect. 114(12), 2006 (1818)

240. C.M. Long, M.A. Nascarella, P.A. Valberg, Environ. Pollut. 181, 271 (2013)

241. D. Massab, S.G. Danelli, P. Brotto, A. Comite, C. Costa, A. Di Cesare, J.-F. Doussin, F. Ferraro, P. Formenti, E. Gatta, L. Negretti, M. Oliva, F. Parodi, L. Vezzulli, P. Prati, Atmos. Meas. Tech. 11, 5885 (2018)

242. S.G. Danelli, M. Brunoldi, D. Massab, F. Parodi, V. Vernocchi, P. Prati, Atmos. Meas. Techn. Disc. 490, $1(2021)$

243. J. Aitken, Nature 14, 384 (1880) 